\title{
A systematic review of mental disorder, suicide, and deliberate self harm in lesbian, gay and bisexual people Michael King*1,2, Joanna Semlyen ${ }^{1}$, Sharon See Tai ${ }^{3}$, Helen Killaspy ${ }^{1,2}$, David Osborn ${ }^{1,2}$, Dmitri Popelyuk ${ }^{1}$ and Irwin Nazareth ${ }^{3,4}$
}

\author{
Address: ${ }^{1}$ Department of Mental Health Sciences, Royal Free and University College Medical School, Hampstead Campus, University College \\ London, London, NW3 2PF, UK, ${ }^{2}$ Camden and Islington Mental Health and Social Care Trust, St Pancras Hospital, London, NW1, UK, \\ ${ }^{3}$ Department of Primary Care and Population Sciences, Royal Free and University College Medical School, Hampstead Campus, University College \\ London, London, NW3 2PF, UK and ${ }^{4}$ General Practice Research Framework, Medical Research Council, 158-60 North Gower Street, London, NW1 \\ 2ND, UK \\ Email: Michael King* - m.king@medsch.ucl.ac.uk; Joanna Semlyen - josemlyen@hotmail.com; Sharon See Tai - s.seetai@pcps.ucl.ac.uk; \\ Helen Killaspy - h.killaspy@medsch.ucl.ac.uk; David Osborn - d.osborn@medsch.ucl.ac.uk; Dmitri Popelyuk - d_popelyuk@hotmail.com; \\ Irwin Nazareth - i.nazareth@pcps.ucl.ac.uk \\ * Corresponding author
}

Published: 18 August 2008

BMC Psychiatry 2008, 8:70

This article is available from: http://www.biomedcentral.com/147I-244X/8/70

(c) 2008 King et al; licensee BioMed Central Ltd.

This is an Open Access article distributed under the terms of the Creative Commons Attribution License (http://creativecommons.org/licenses/by/2.0), which permits unrestricted use, distribution, and reproduction in any medium, provided the original work is properly cited.

\begin{abstract}
Background: Lesbian, gay and bisexual (LGB) people may be at higher risk of mental disorders than heterosexual people.

Method: We conducted a systematic review and meta-analysis of the prevalence of mental disorder, substance misuse, suicide, suicidal ideation and deliberate self harm in LGB people. We searched Medline, Embase, Psyclnfo, Cinahl, the Cochrane Library Database, the Web of Knowledge, the Applied Social Sciences Index and Abstracts, the International Bibliography of the Social Sciences, Sociological Abstracts, the Campbell Collaboration and grey literature databases for articles published January 1966 to April 2005. We also used Google and Google Scholar and contacted authors where necessary. We searched all terms related to homosexual, lesbian and bisexual people and all terms related to mental disorders, suicide, and deliberate self harm. We included papers on population based studies which contained concurrent heterosexual comparison groups and valid definition of sexual orientation and mental health outcomes.
\end{abstract}

Results: Of 13706 papers identified, 476 were initially selected and 28 (25 studies) met inclusion criteria. Only one study met all our four quality criteria and seven met three of these criteria. Data was extracted on 214,344 heterosexual and II,97I non heterosexual people. Meta-analyses revealed a two fold excess in suicide attempts in lesbian, gay and bisexual people [pooled risk ratio for lifetime risk $2.47(\mathrm{Cl} \mathrm{I.87,} \mathrm{3.28)].} \mathrm{The} \mathrm{risk} \mathrm{for} \mathrm{depression} \mathrm{and} \mathrm{anxiety} \mathrm{disorders} \mathrm{(over} \mathrm{a}$ period of 12 months or a lifetime) on meta-analyses were at least I.5 times higher in lesbian, gay and bisexual people (RR range I.54-2.58) and alcohol and other substance dependence over I 2 months was also I.5 times higher (RR range I.5 I4.00). Results were similar in both sexes but meta analyses revealed that lesbian and bisexual women were particularly at risk of substance dependence (alcohol I2 months: RR 4.00, Cl 2.85, 5.6I; drug dependence: RR 3.50, Cl I.87, 6.53; any substance use disorder RR 3.42, $\mathrm{Cl}$ I.97-5.92), while lifetime prevalence of suicide attempt was especially high in gay and bisexual men (RR 4.28, Cl 2.32, 7.88).

Conclusion: LGB people are at higher risk of mental disorder, suicidal ideation, substance misuse, and deliberate self harm than heterosexual people. 


\section{Background}

Lesbian, gay and bisexual (LGB) people appear to be at greater risk than heterosexual people of mental disorders and suicidal behaviour $[1,2]$. LGB people are subject to institutionalised prejudice, social stress, social exclusion (even within families) and anti-homosexual hatred and violence and often internalise a sense of shame about their sexuality $[1,2]$. Lifestyle factors such as alcohol and drugs misuse also increase the risk of morbidity [1] as well as suicide attempts [3]. Deliberate self harm (DSH) is intentional self poisoning or injury, irrespective of the apparent purpose of the act. DSH is one of the leading causes of acute medical admissions in the UK. Incidence rose steadily from the mid 1980s to the late 1990s with a peak incidence rate of 400 per 100,000 per annum [4], one of the highest in Europe. However there is evidence of a steady drop in suicide in England (and other developed countries) since 2000 [5]. The evidence on mental health of LGB people is inconclusive partly because of the difficulty of defining or recruiting samples that are representative of all non-heterosexual people. Specific methodological obstacles include variation in the definition of sexual orientation, DSH and mental illness; difficulty in achieving random samples; reliance on participants' recall; unwillingness of people to be open about their sexual orientation; lack of information on sexuality in suicide victims who are part of psychological post mortem studies; the complexity of choosing appropriate comparison groups and poor or absent adjustment for confounding influences such as substance use and personality factors.

There is an urgent need to quantify the risk for mental disorder, DSH and suicide in LGB people, to understand the precipitants and to examine the efficacy of prevention efforts. There is also a need to make a judgement about the quality of the evidence available. We undertook a systematic review of the world literature on risk of mental disorder, substance misuse, DSH, suicidal ideation and suicide in LGB people. These parameters are the main ones reported in the literature and provide a comprehensive picture of mental health and well being.

\section{Hypothesis}

Gay, lesbian and bisexual people have higher risks than heterosexual people of mental disorder, substance misuse and dependence, suicide, suicidal ideation and DSH.

\section{Objective}

To undertake a systematic review of the international research literature to establish whether LGB people are at higher risk of mental disorder, substance misuse, suicide, suicidal ideation and DSH than heterosexual people and to quantify this risk.

\section{Method}

We searched for studies of mental disorder, drug and alcohol misuse and dependence, DSH, suicidal ideation and/ or suicide in general (community) or selected (e.g. student) populations in which sexual orientation was reported. We use the following abbreviations: GB (gay and bisexual men); LB (lesbians and bisexual women) and LGB (lesbians, gay men and bisexual men and women).

\section{Data sources}

We searched Medline, Embase, PsycInfo, Cinahl, the Cochrane Library Database, the Web of Knowledge, the Applied Social Sciences Index and Abstracts, the International Bibliography of the Social Sciences, Sociological Abstracts, the Campbell Collaboration and grey literature databases for articles published between January 1966 and April 2005. We searched all terms related to homosexual, lesbian and bisexual people and all terms related to mental disorders, suicide, and deliberate self harm. No language limits were imposed. A full internet search was also carried out using Google and Google Scholar and authors were contacted where necessary. We also searched the reference lists of relevant papers.

\section{Study selection \\ Eligibility}

We included papers that provided valid definition of sexual orientation and mental health outcomes. Random sampling is hampered by participants' reluctance to disclose their sexual orientation and the small numbers of LGB people recruited. Thus other methods such as snowball sampling (initial LGB participants recruit other LGB people in successive waves) were regarded as acceptable if the study met other inclusion criteria. We included studies in which people defined themselves as: gay, lesbian, homosexual, bisexual and/or in which they reported levels of same sex attraction or behaviour. We excluded studies based in clinical or psychological services. We only included studies in which there was a concurrent heterosexual comparison group within either a cohort, case-control or cross sectional study. Outcomes were defined as: a) a psychiatric disorder according to the International Classification of Diseases or the American Psychiatric Association's Diagnostic and Statistical Manual (including substance misuse disorders); b) scores or a recognised threshold for psychiatric morbidity on standardised scales (including alcohol or drug dependence); c) alcohol misuse: consumption above UK Government recommended maximum weekly limits (21 units men, 14 units women); d) suicide (the intentional taking one's own life) e) suicidal ideation (i.e. thoughts of taking one's life without acting on them); f) DSH: intentional self poisoning or injury irrespective of the apparent purpose of the act [5]. These outcomes were extracted for both the LGB and het- 
erosexual comparison groups as cumulative incidence rates in prospective cohort studies or period prevalence rates in cross sectional studies.

Screening process and assessment of eligibility

The titles and abstracts of citations were screened by JS and DP and those not meeting eligibility criteria, unpublished dissertation theses, case reports, letters, commentaries, or review papers were excluded. Decisions on papers included in the final review were made by pairs of authors and disagreements discussed at steering group meetings involving all authors.

\section{Data extraction}

At least two of the authors extracted data from each paper on study setting, study design, population and sampling details, attrition and response rate. We recorded the definition of LGB sexual orientation (same sex attraction; same sex behaviour; self identification as lesbian gay or bisexual; a score above zero on the Kinsey scale [6]) and outcome (mental disorder, substance misuse, DSH, suicidal ideation and suicide). Where appropriate we extracted prevalence estimates and/or odds ratios; for continuous data we extracted means and standard deviations. In instances of disagreement, each case was discussed by all authors.

\section{Quality of studies reviewed}

We used the Cochrane Handbook's general guidance on non-experimental studies to inform our choice of quality indicators ( 2 indicating higher quality than 1 ). We examined for: sampling: non random $=1$, random $=2$; represent ativeness: response rates: $<60 \%=1,60 \%$ or more $=2$; population definition: selected sample (e.g. school students) $=1$; general population $=2$ and sample size $:<100 \mathrm{LB}$ or GB people $=1,>100 \mathrm{LB}$ or GB people $=2$.

\section{Data synthesis}

Studies were grouped according to lifetime or 12 month prevalence and where possible we analysed outcomes for lesbians, gay men and bisexual people separately and collectively. We calculated risk ratios and attributable risks (differences between rates in LGB and non LGB people) from extracted prevalence data. We examined suicide attempts when reported instead of or in addition to DSH. For continuous outcomes we calculated the effect size as standardised mean difference in scores between LGB people and controls.

\section{Meta-analytic approach}

We adopted standard methods for conducting meta-analyses where there were two or more studies with useable outcome data. We used a random effects model which used inverse variance methods to calculate the pooled effect estimate in which the weight given to each study is the inverse of the variance of the study estimate together with the common heterogeneity variance. We quantified the effect of heterogeneity [7] by using $I^{2}$ which describes the percentage of total variation across studies that can be attributed to heterogeneity rather than chance [8].

\section{Results}

From 13706 citations identified, 476 papers were retrieved of which 429 were excluded (figure 1). Eightythree of those excluded were controlled studies [36-120], $122-123]$; two $[39,40]$ were excluded because the data were repeated elsewhere [29]; seven did not meet sampling criteria [36-38,75,76,118,119]; 34 did not report suicide, DSH or diagnostic outcomes [41-74]; 37 involved unrepresentative populations [77-113] and three on closer inspection did not concern LGB people [114-116]. There were insufficient data in three studies on completed suicide to include it as an outcome in the review. One that involved suicide in a cohort of bisexual and gay men was excluded because it was uncontrolled [117]; one study comparing clinical characteristics of a subpopulation of gay and non-gay male suicides was excluded because of

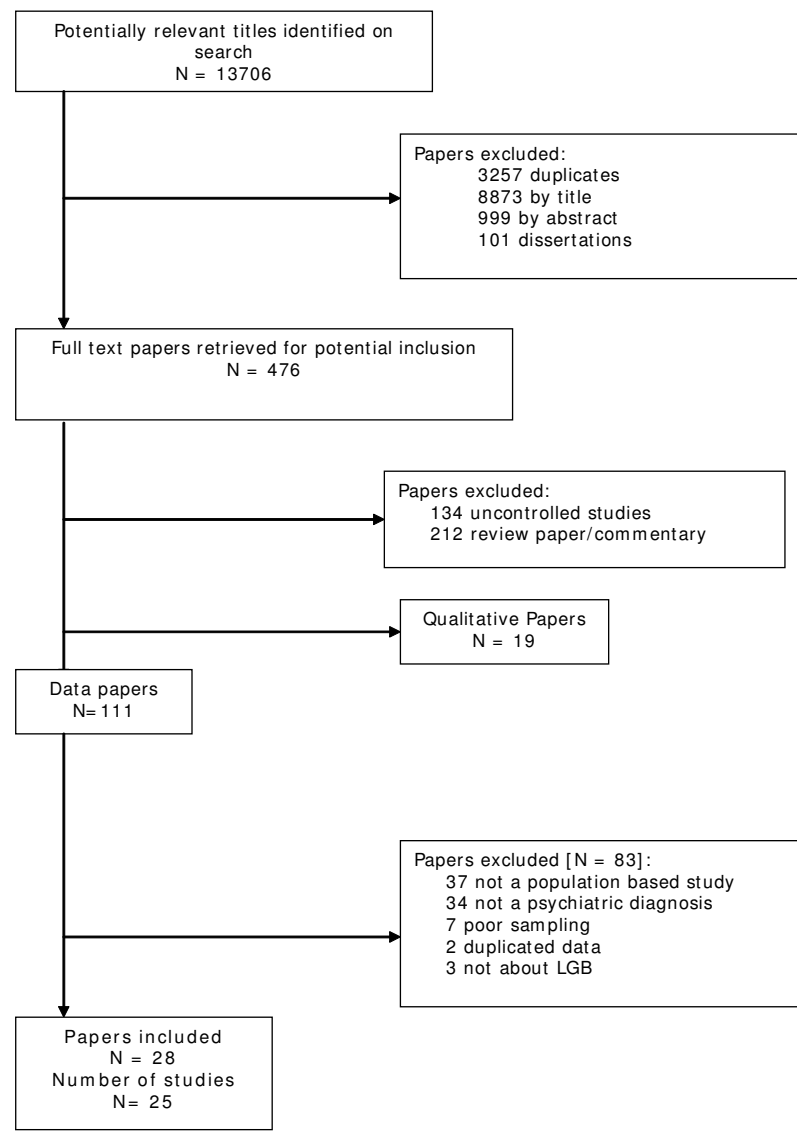

Figure I Study inclusion process. 
sampling concerns [118] and a psychological autopsy study carried out in 1995 [119] was excluded as it contained only three gay male suicides.

\section{Study characteristics}

Twenty-eight papers [1,9-35] reporting on 25 studies [1,9$12,14,15,17-31,33-35]$ met our inclusion criteria (Additional file 1$)$; six papers $[12,13,15,16,31,32]$ reported data on three studies. Five studies could not be included in a meta-analysis because the data were not extractable or in a format that allowed comparison $[10,11,22,27,34]$. Three of the four longitudinal cohorts $[11,18,33]$ presented nested cross-sectional data on sexual orientation and mental health at one time point. One cohort study, however, conducted a longitudinal analysis of cumulative incidence of suicidal attempts but did not provide extractable data [34]. No case-control studies were identified. The studies were conducted in seven countries in North America, Europe and Australasia, with most based in the USA $(17 / 25,67 \%)$. The papers were published between 1997 and 2004, with two thirds published between 2000 and 2003. Participation rates ranged from 25\% [23] to $95 \%[28]$.

\section{Population}

The papers contained data on 214,344 heterosexual and 11,971 non heterosexual people aged 12 and over. Four studies involved people aged under $18[10,17,29,30]$ and 18 involved people under 25 years. Four studies included only women $[11,20,24,26]$, three only men $[9,14,21]$ and 18 both sexes. Eight studies [10,17,21,25,26,28-30,34] concerned high school and college students. Of the 21 cross sectional studies, nine used random sampling $[9,15,19,20,22,25,26,31,35]$; two multi-stage sampling $[12,14]$; two snowball sampling $[1,24]$; one systematic sampling (i.e. 26 years follow up data on a birth cohort) [23]; and seven did not specify their sampling method $[10,17,21,27-30]$.

\section{Definition of sexuality}

Sexuality was defined in a number of ways even within the same study: four studies used same sex attraction $[24,30,33,34] ; 13$ used same sex behaviour $[9,10,12,14,17-19,21,24,29-31,34,35] ; 15$ used participant self identification $[1,9-11,15,18,20,22,23,25-29]$; and three used a score above zero on the Kinsey scale $[1,28,34]$ (see Additional file 1). Nine studies used two definitions of sexual orientation [1,9,10,18,24,28-30,35] and one used three definitions [34]. Self-identified sexuality was based on the categories heterosexual, homosexual or bisexual $[9,15,18,20,22,23,28]$ or included the choices gay or lesbian $[1,10,11,25-27,29]$. Eighteen studies used a specific time frame to assess sexuality. Lifetime same sex attraction was assessed in two studies [30,33]; current same sex attraction assessed in four [24,33-35] and in one study both were assessed [33]. Same sex behaviour was assessed as occurring 'in the last year' in two studies $[12,24]$, 'in the last five years' in one study [19] or 'ever' in nine studies $[9,10,14,17,18,21,29,30,34]$.

\section{Outcomes of interest}

Fifteen studies assessed suicide attempts or DSH $[1,9,10,14,17-19,21,23,24,28-30,33,34]$ and 12 assessed suicidal ideation $[14,17-19,21-24,26,28,30,33]$. Data on mental disorder were assessed in 10 studies $[1,9,11,12,14,15,18,19,22,31]$, substance dependence in six studies $[12,15,18,19,31,35]$ and substance misuse in nine studies $[1,19,20,22,25-27,31,35]$. Eighteen studies assessed more than one of these outcomes $[1,9,12,14,15,17-19,21-24,26,28,30,31,33,35]$ and one study assessed all [19]. Risk ratios and attributable risks were calculated for all outcomes of interest (figures 2, 3, 4, $5,6,7,8,9)$.

\section{Quality of cross sectional studies}

Nine studies were based on random populations but only seven of these were sampled from the community rather than from specific groups (e.g. schools). Only four of these reported responses of at least $60 \%$ and of these only one [19] sampled 100 or more LGB people (table 1).

\section{Data syntheses}

\section{Suicide attempts and DSH}

Only one cohort study [34] reported cumulative incidence of suicide attempts over two years in 2924 Norwegian school youths. They reported an odds ratio of 4.69 (95\% CI 2.29, 10.62) for LB girls after adjustment but no significant differential for BG boys.

Meta-analyses of cross-sectional studies of lifetime suicide attempts demonstrated increased risk in all groups when compared to heterosexuals but there was substantial heterogeneity when these data were combined for both sexes and for men only (Figure 2). Attributable risk ranged from 0.03 to 0.25 and was higher in men than women. Studies in this analysis were limited by small samples $[9,14,18,33]$ or selection bias $[18,23,28,33]$ (Table 1 ). One small study that met all but one quality criteria showed a high risk of suicide attempts in men (Figure 2) [9]. Meta-analysis in women demonstrated 1.82 times increased risk of lifetime suicide attempts in lesbians and bisexuals compared to controls and showed little heterogeneity (Figure 2). However, all the studies failed to meet several of our quality indicators.

Risk ratios for 12 month prevalence of suicide attempts ranged from 1.96 to 2.76 (men 2.23 to 2.53; women 1.94 to 2.46), while attributable risk ranged from 0.01 to 0.14 (men 0.01 to 0.03 ; women 0.01 to 0.07 ). The pooled estimate for men and women was 2.56 (Figure 2) with similar 
Suicide attempts (lifetime prevalence) in men and women

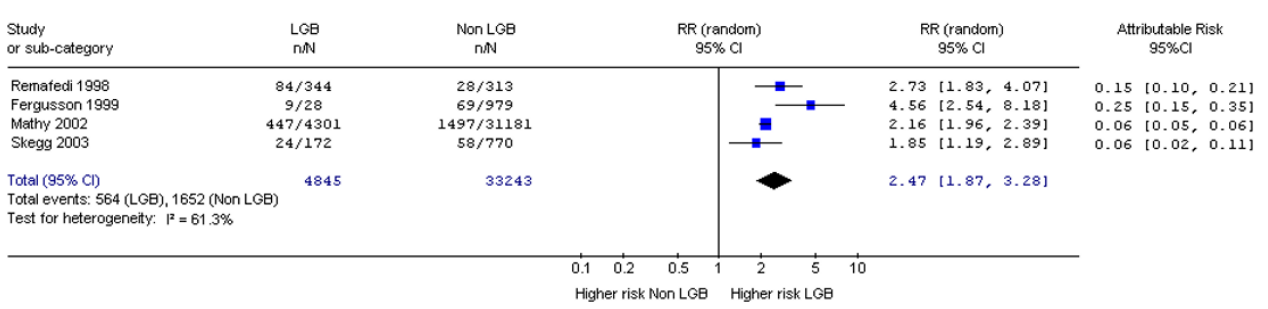

Suicide attempts (lifetime prevalence) in men only

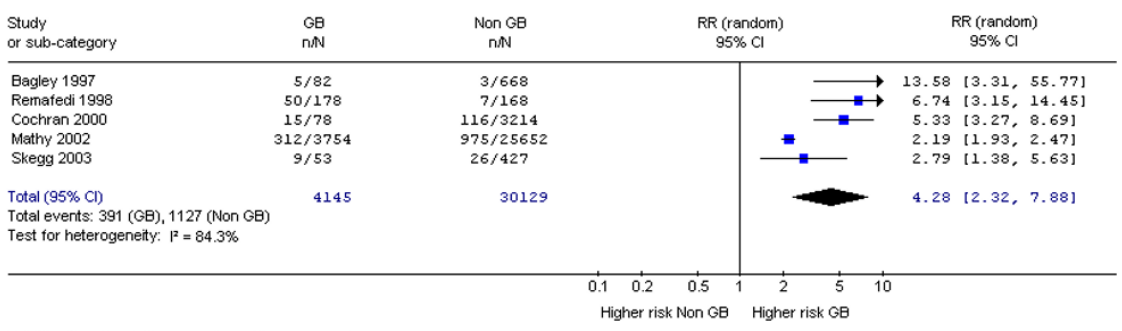

Suicide attempts (lifetime prevalence) in women only

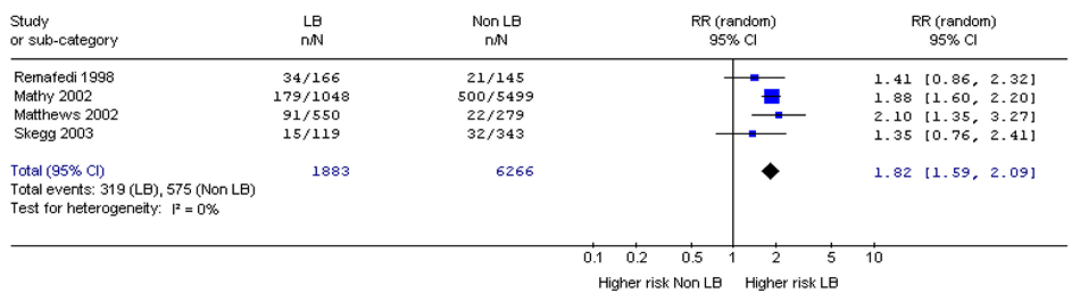

Suicide attempts (12 month prevalence) in men and women

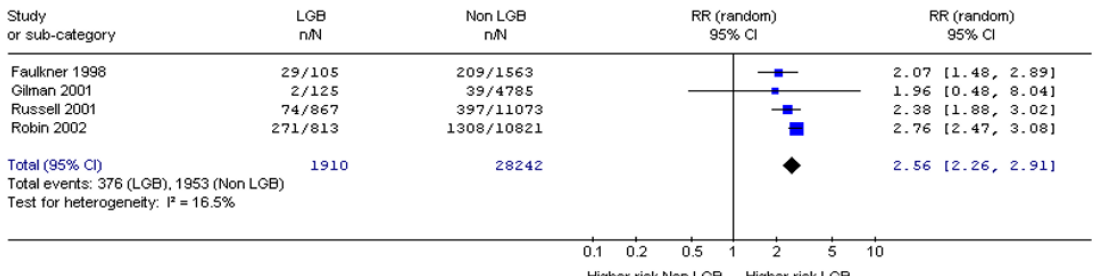

\author{
Attributable Risk \\ $95 \% \mathrm{Cl}$ \\ $0.06[-0.03,0.15]$ \\ $0.08[0.06,0.10]$ \\ $0.03[-0.03,0.10]$
}

Higher risk Non LGB Higher risk LGB

Suicide attempts ( 12 month prevalence) in men only

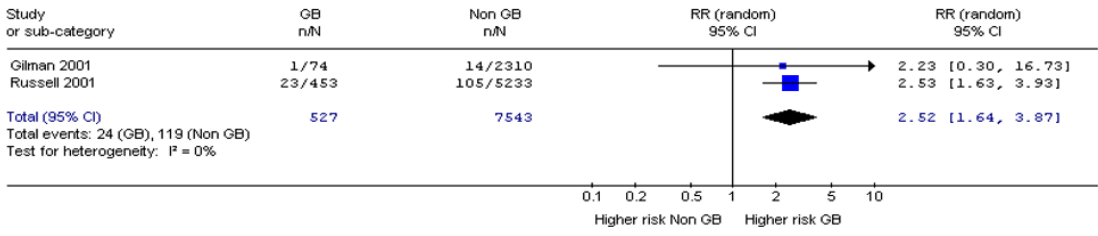

Suicide atternpts ( 12 month prevalence) in women only

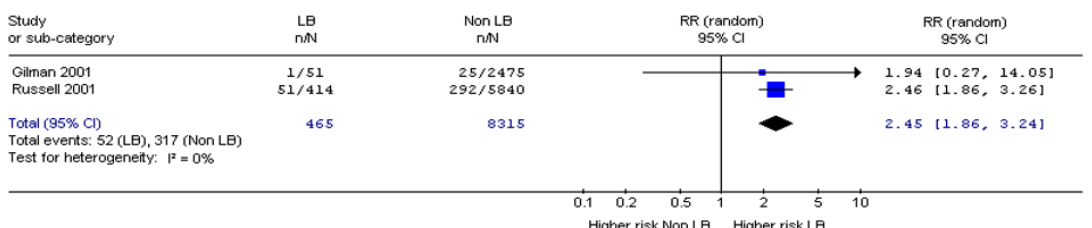

Figure 2

Forest plots for lifetime and 12 month prevalence of suicide attempts. 


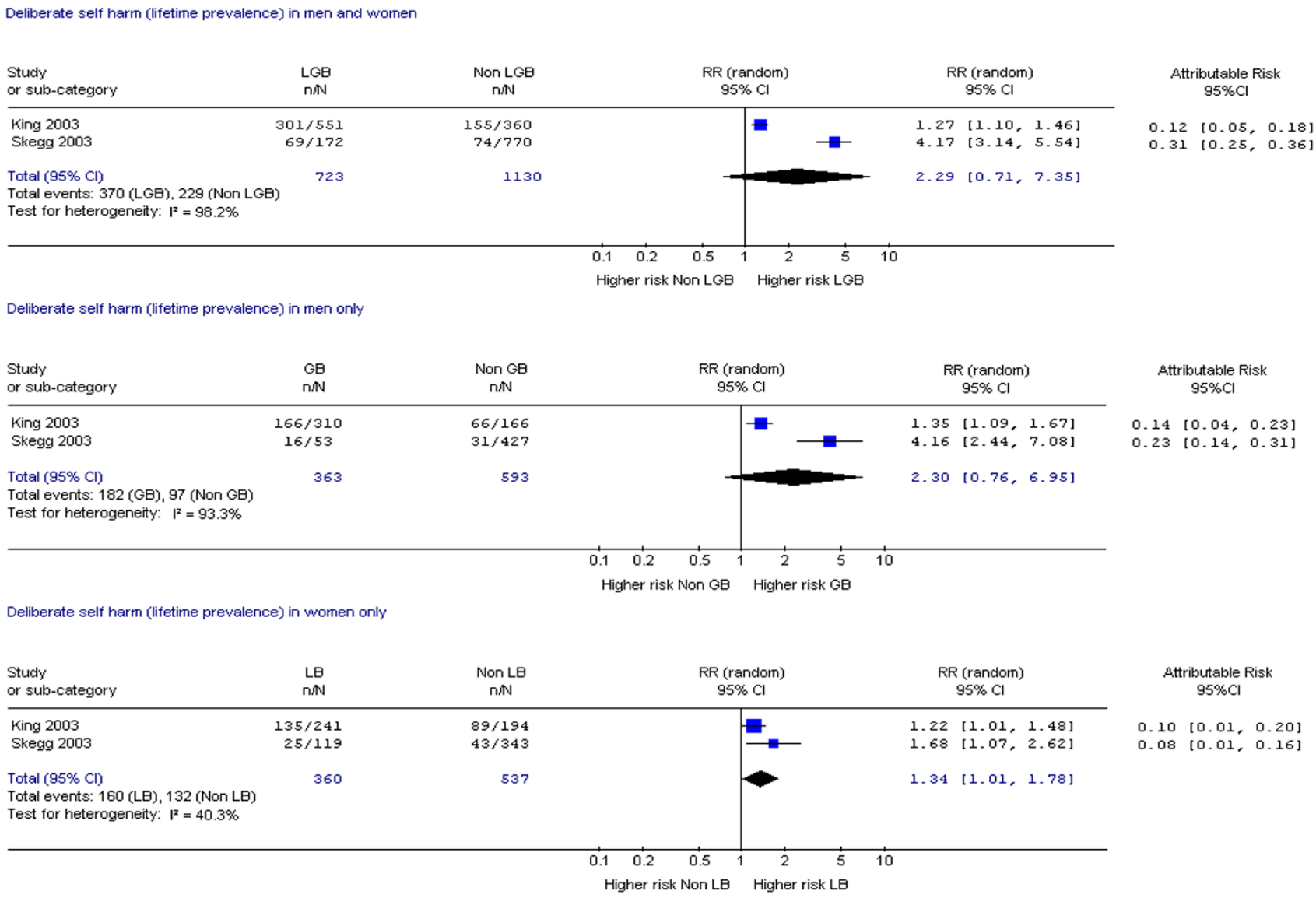

\section{Figure 3}

Forest plots for lifetime prevalence of deliberate self harm.

values for LB and GB people and all showed little or no heterogeneity. The highest quality study [19], however, showed a non significant risk ratio for all groups.

Only two studies reported lifetime prevalence of DSH $[1,33]$ (Figure 3) and meta-analyses of these data produced equivocal results. One further study that met all but one of our quality criteria reported elevated risk of lifetime prevalence of DSH and/or suicide attempts [9] in gay rather than bisexual men (RR: Gay =3.61, CI 1.86, 7.01; Bisexual men $=1.95$, CI 0.73, 5.19).

\section{Suicidal ideation}

Meta-analyses of lifetime prevalence of suicidal ideation revealed risk ratios of 2.04 for both sexes (range: both sexes 1.72 to 2.42 ; men 2.0 to 4.10 ; women 1.75 to 2.10 ) with considerable heterogeneity. Attributable risk ranged from 0.10 to 0.40 (Figure 4). All studies included in this analysis were limited by selection bias $[23,24]$ and small samples $[12,17]$.

The combined meta-analysis of 12 month prevalence of suicidal ideation contained some heterogeneity in both sexes and in women, but none in men. The risk ratio in both sexes was 1.71 (men 1.64; women 2.31) while attributable risk ranged from 0.02 to 0.21 (men 0.02 to 0.13 ; women 0.02 to 0.21 ). One study that met all four quality criteria [19] demonstrated over three times the risk in women but not in men. The other studies were limited by selection of very young populations $[17,28,30,33,26]$ or low participation rates [26].

In summary, there were elevated risks for suicide attempts and ideation in LGB people but quality of studies was limited. Data from higher quality studies showed higher cumulative incidence of suicide in LB school girls, increased lifetime risk of suicide attempts in GB men and increased 12 months risk of suicidal ideation in LB women.

\section{Mental disorders - depression}

Three studies reported lifetime prevalence of depression $[14,18,31]$. Increased risk of lifetime depression was observed in both sexes and men with little heterogeneity in the analyses (Figure 5). One of the two studies that met all but one quality criteria demonstrated a risk ratio of 2.2 


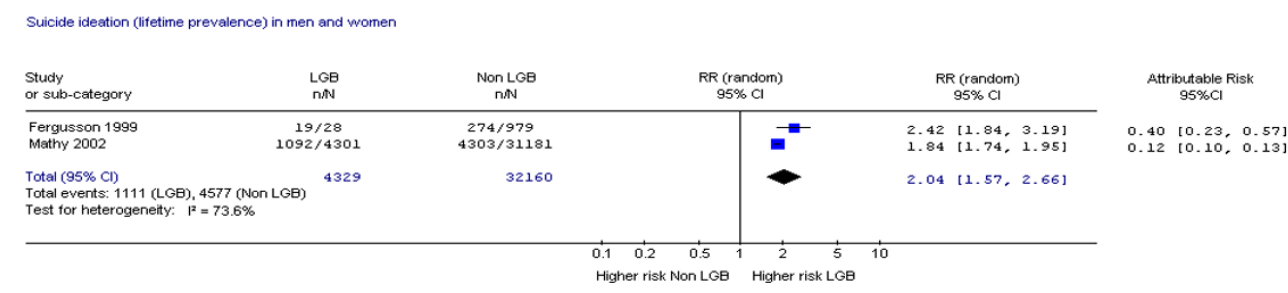

\begin{tabular}{|c|c|c|c|c|}
\hline $\begin{array}{l}\text { Study } \\
\text { or sub-category }\end{array}$ & $\begin{array}{l}\mathrm{GB} \\
\mathrm{GN}\end{array}$ & $\underset{\mathrm{N}}{\mathrm{Non} G \mathrm{~N}}$ & $\begin{array}{l}\mathrm{RR}(\mathrm{random}) \\
95 \% \mathrm{Cl}\end{array}$ & $\begin{array}{l}\text { RR (random) } \\
95 \% \mathrm{Cl}\end{array}$ \\
\hline $\begin{array}{l}\text { Cochran } 2000 \\
\text { Mathy } 2002\end{array}$ & $\begin{array}{l}32 / 78 \\
848 / 3754\end{array}$ & $\begin{array}{c}553 / 3214 \\
3180 / 25652\end{array}$ & $=$ & $\begin{array}{l}2.38 \quad[1.81,3.14] \\
1.82[1.70,1.95\}\end{array}$ \\
\hline $\begin{array}{l}\text { Total ( } 95 \% \mathrm{Cl}) \\
\text { Total everts: } 880 \text { (G), } 3733 \text { (Non } \mathrm{GB} \text { ) } \\
\text { Test for heterogeneity: } \quad \mathrm{I}^{\mathrm{I}=71.0 \%}\end{array}$ & 3832 & 28866 & - & $2.01[1.56,2.60\}$ \\
\hline
\end{tabular}
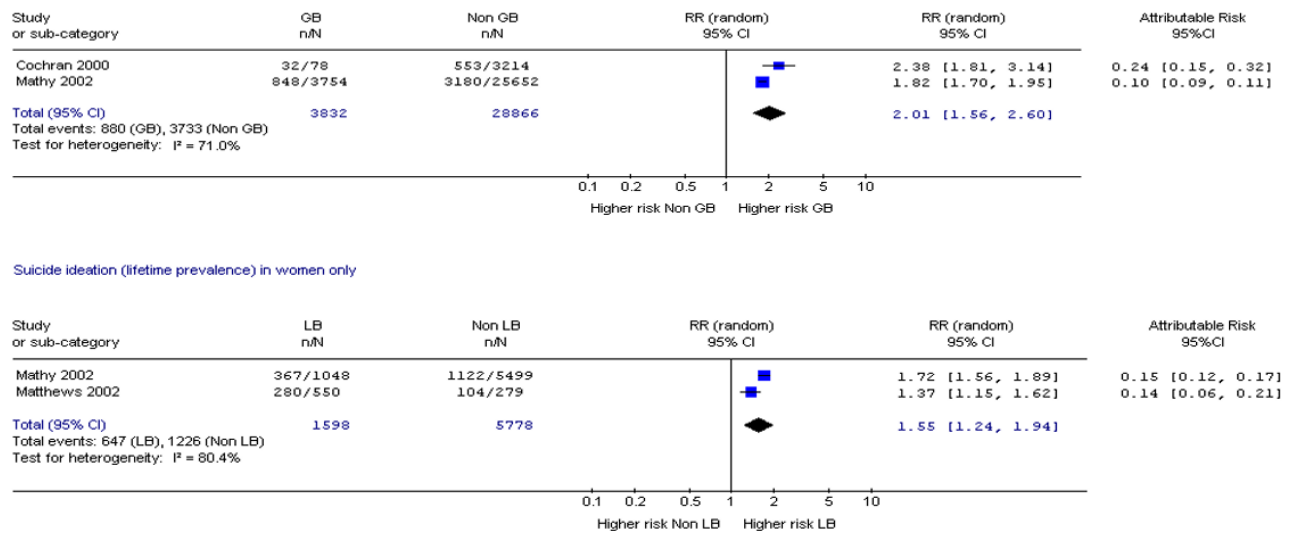

Suicide Ideation (12 month prevalence) in men and women

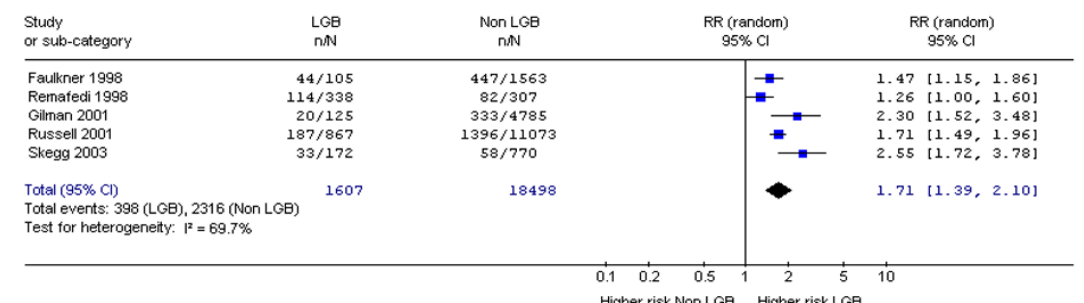
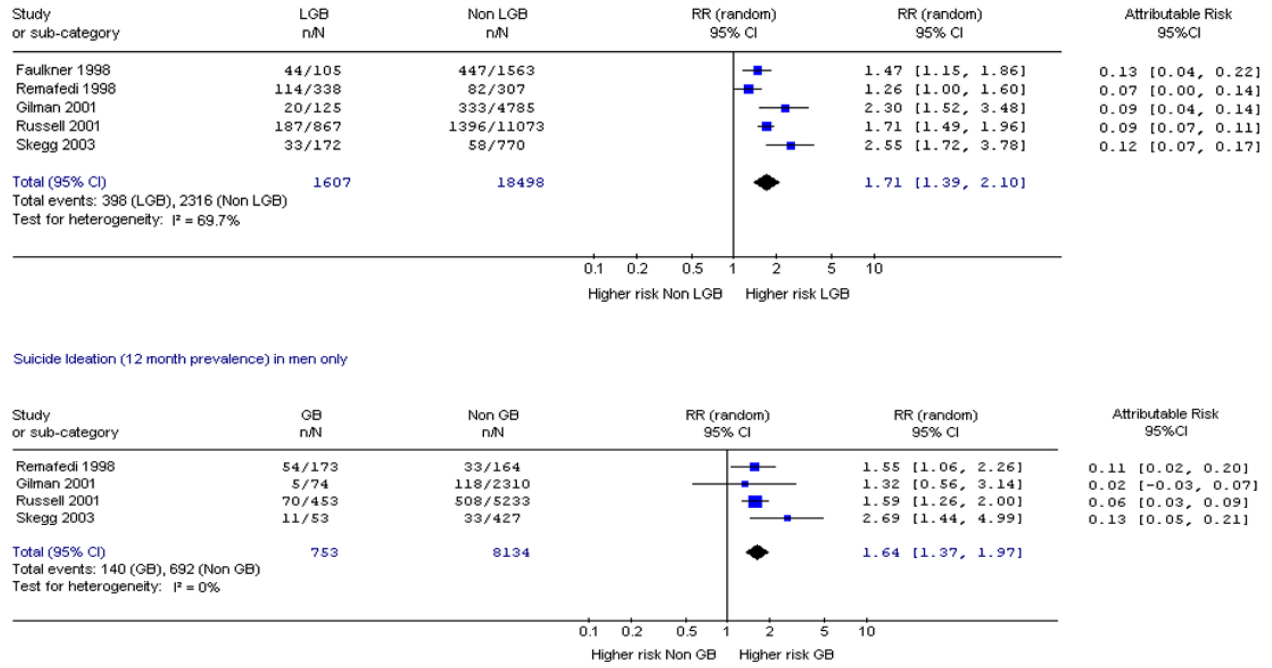

$95 \% \mathrm{Cl}$

$0.11[0.02,0.201$ $0.06[0.03,0.09]$ $0.13[0.05,0.21]$

Suicide Ideation (12 month prevalence) in women only

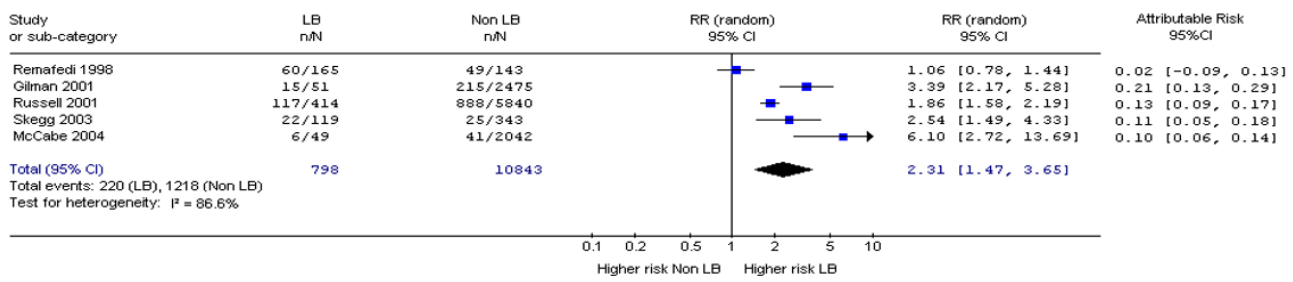

Figure 4 Forest plots for lifetime and 12 month prevalence of suicide ideation. 
Depression (lifetime prevalence) in men and women

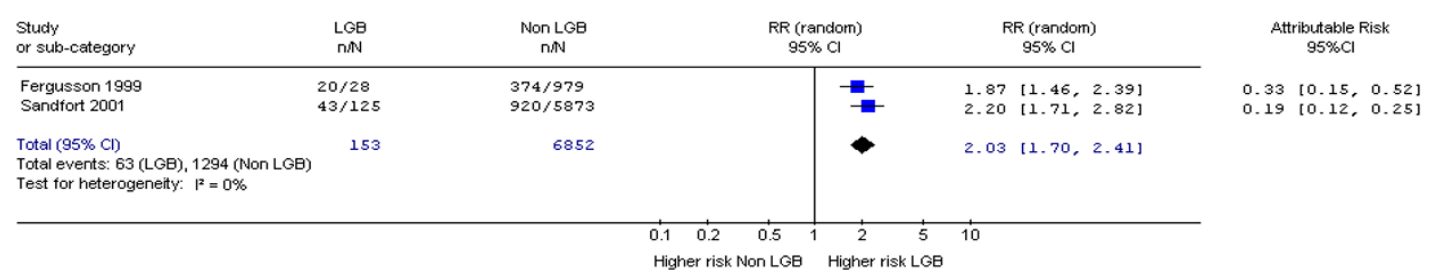

Depression (lifetime prevalence) in men only

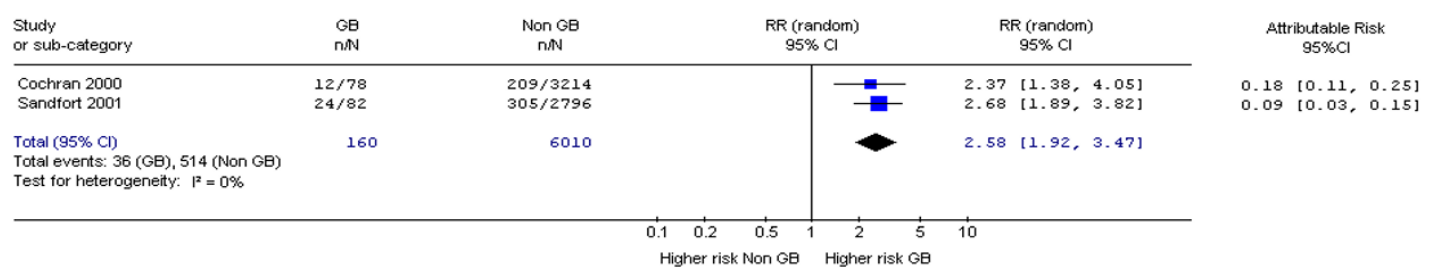

Depression (12 months prevalence) in men and women

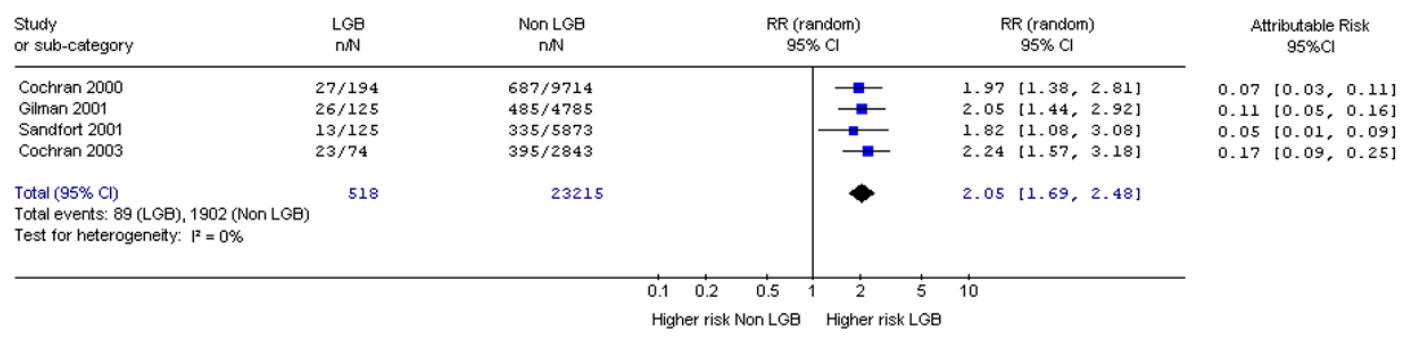

Depression (12 months prevalence) in men only

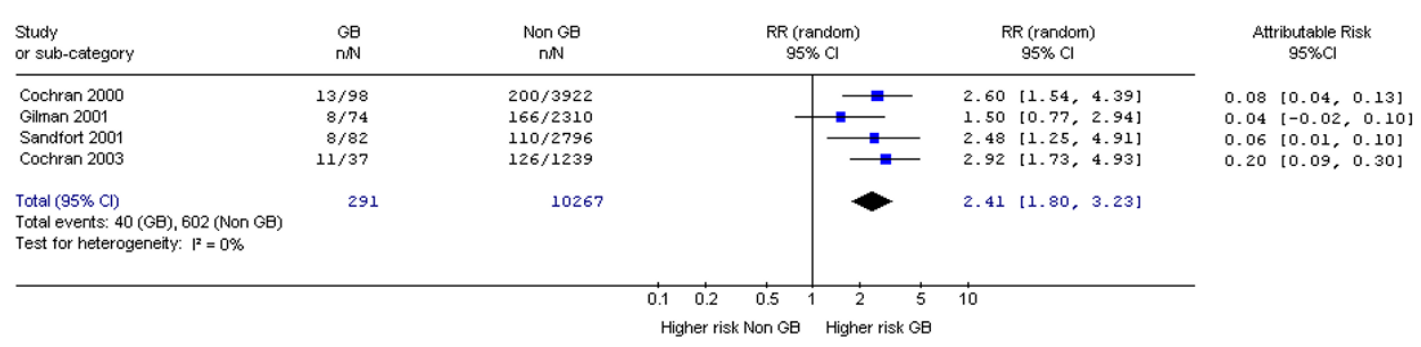

Depression (12 months prevalence) in women only

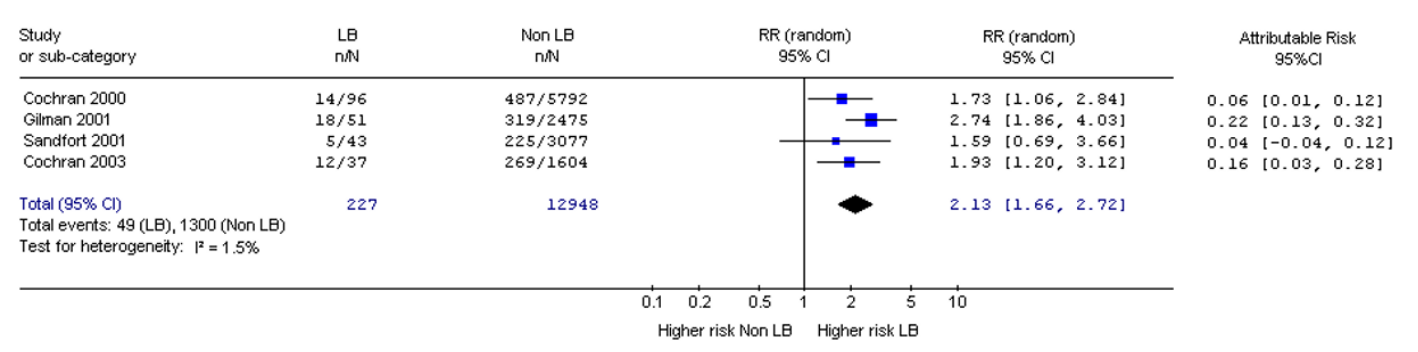

Figure 5

Forest plots for lifetime and 12 month prevalence of depression. 
Anxiety (12 months prevalence) in men and women

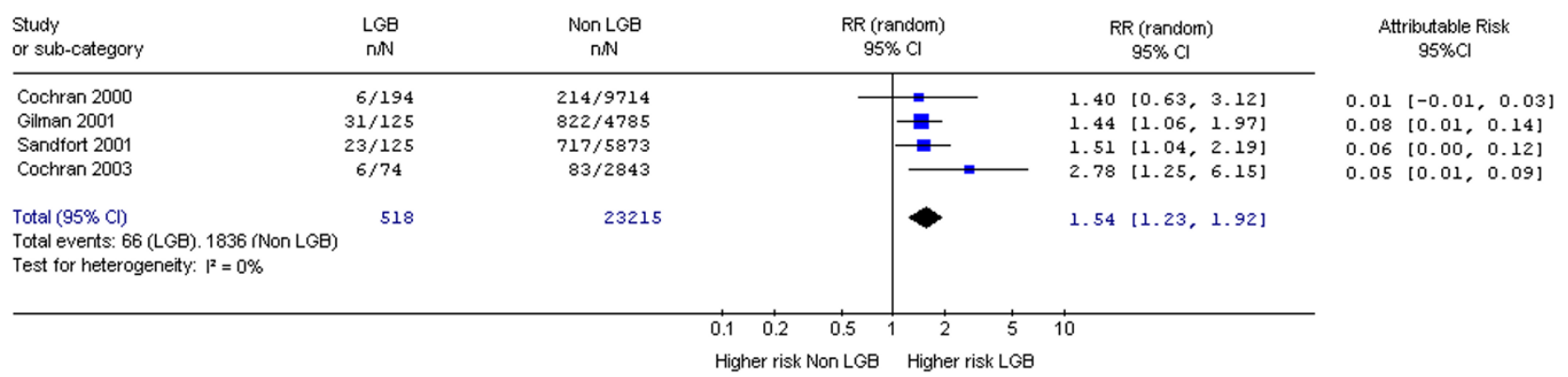

Anxiety (12 months prevalence) in men only

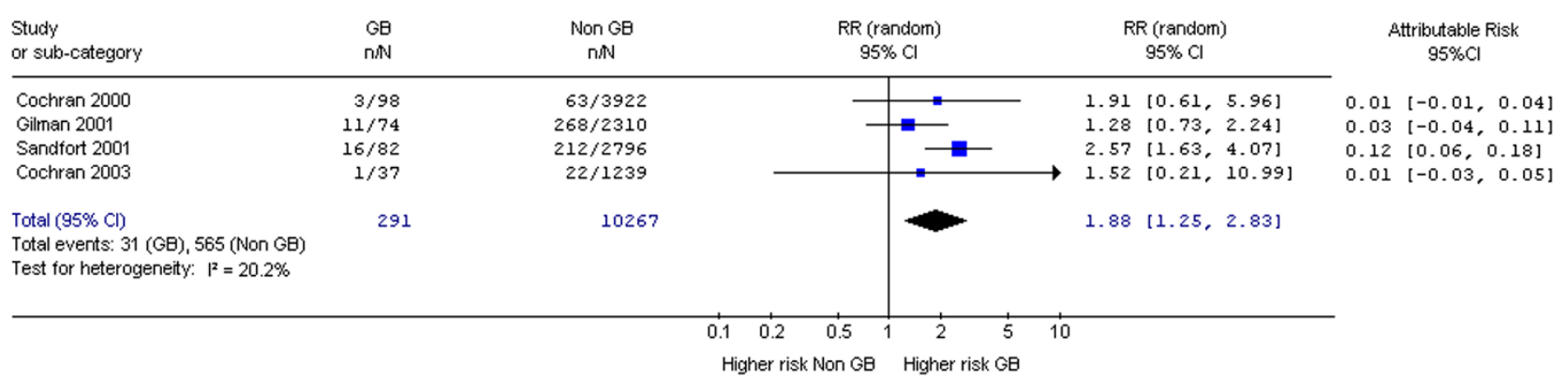

Anxiety ( 12 months prevalence) in women only

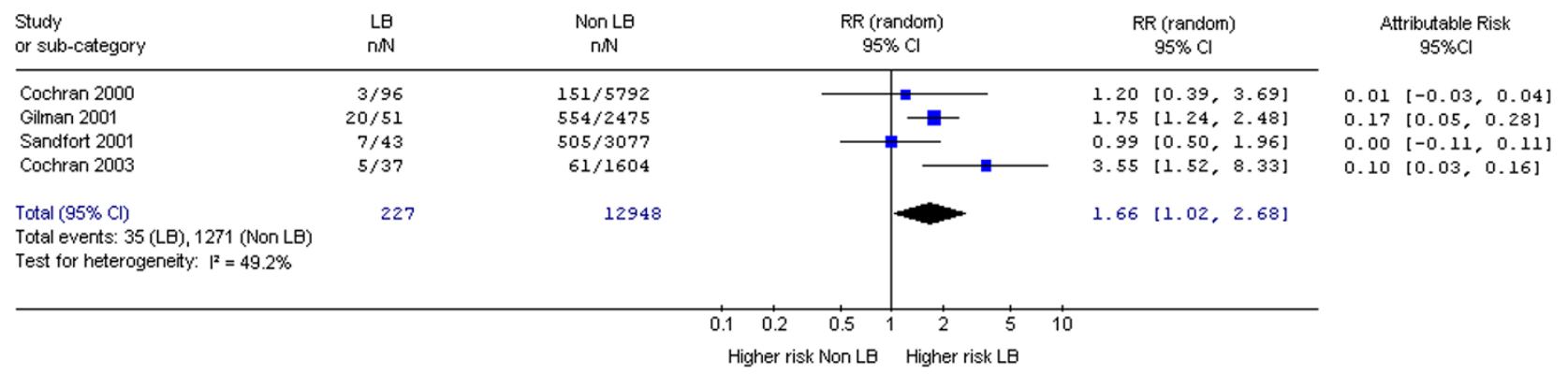

\section{Figure 6}

Forest plots for 12 month prevalence of anxiety.

in both sexes; 2.68 in men (Figure 5); and 2.21 (CI 1.57, 3.12 ) in women [31].

The risk of 12 months prevalence of depression in LGB people on meta-analysis was at least twice that of heterosexual controls with little heterogeneity (Figure 5). All studies in this analysis were of good quality based on general population samples with high participation rates. Risk ratios ranged from 1.57 to 3.74 (men 1.57 to 3.74 ; women 1.67 to 3.69 ) and attributable risk from two stud- ies ranged from 0.04 to 0.20 (men 0.04 to 0.20 ; women 0.04 to 0.22 ). The only study that met the highest standard on the four quality criteria demonstrated significantly higher risk ratios and attributable risk for women but not men [19]. Lastly, a study of 45 gay and 37 bisexual men that recorded depression on a standardised scale and met all but one of our quality criteria showed a small but positive effect size indicating more depression in gay or bisexual men (standardised mean difference in depression score 0.16) [9]. 
Alcohol Dependence (12 months prevalence) in men and women

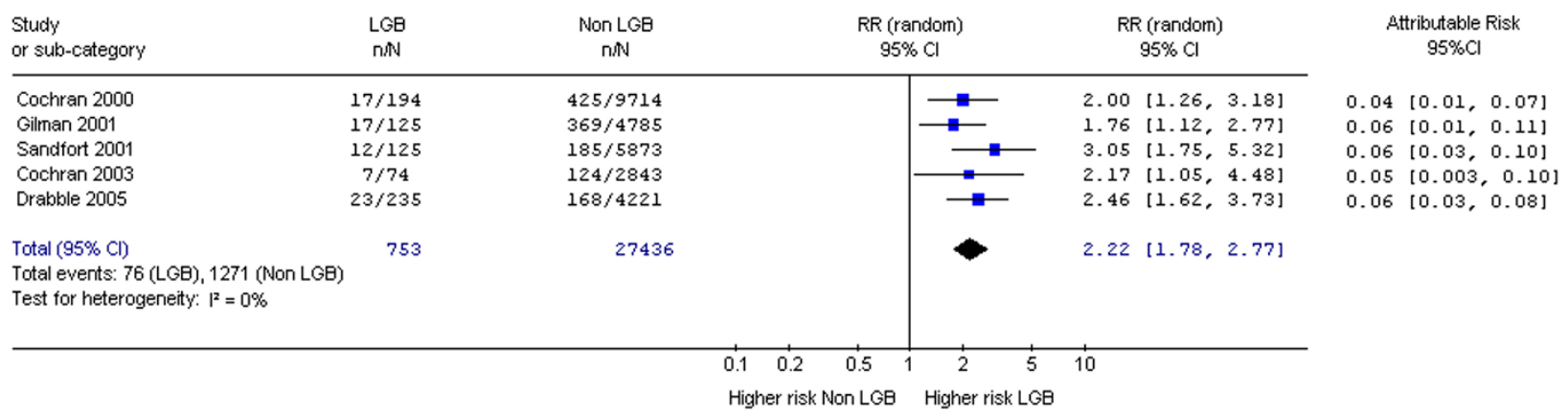

Alcohol Dependence (12 months prevalence) in men only

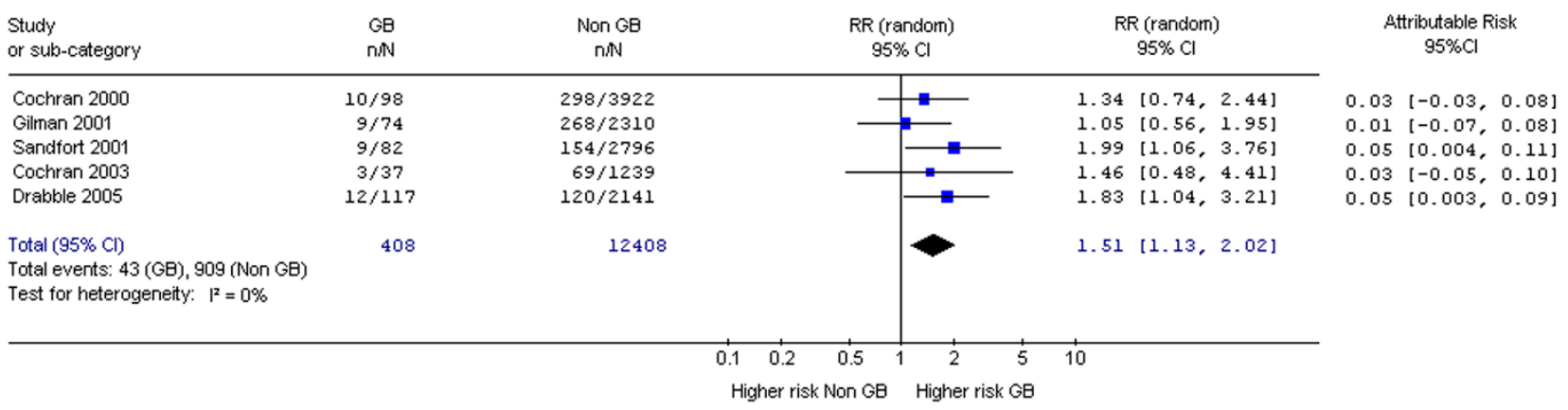

Alcohol Dependence (12 months prevalence) in women only

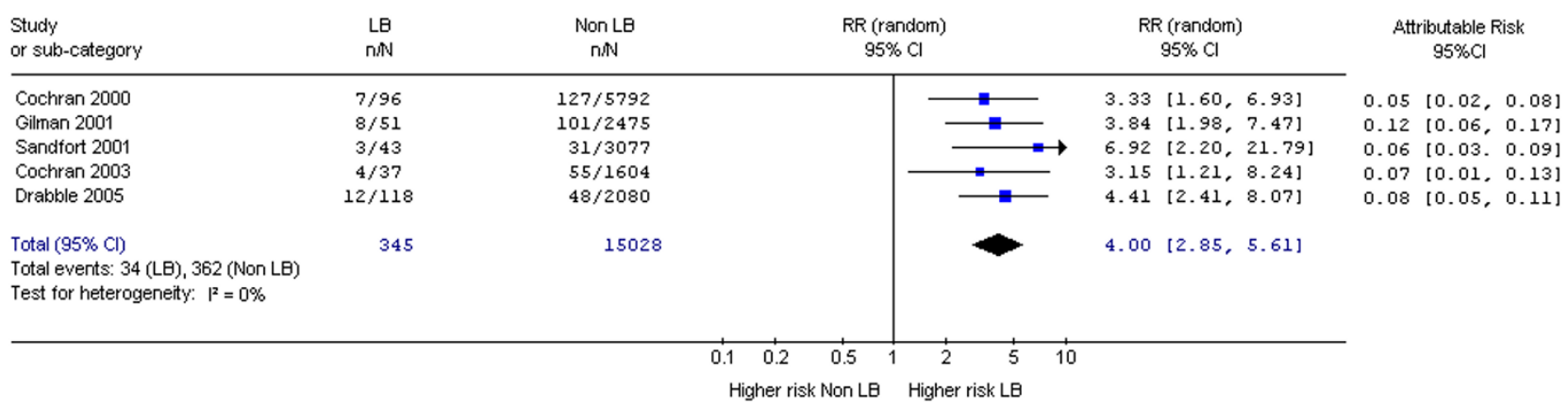

Figure 7

Forest plots for 12 month prevalence of alcohol dependence.

\section{Mental disorders - anxiety}

Two studies reported lifetime prevalence of any anxiety disorder and both met all but one of the quality criteria $[18,31]$. Although their data could not be combined in a meta-analysis, increased risk was reported in both sexes (RR 2.28 CI 1.25, 4.21) [18] and in men (RR 2.40, CI 1.72, 3.35) [31], but not in women (RR 1.02, CI 0.61, 1.70) [31]. The meta-analyses of data on 12 month prevalence of any anxiety disorder (Figure 6) resulted in a pooled RR of 1.54 for both sexes and 1.88 in men with little heterogeneity. Attributable risk ranged from 0.00 to 0.17 (men 0.01 to 0.12 ; women 0.00 to 0.17 ). The result in women was less convincing because of heterogeneity. The only study of the four in this analysis that met the highest of all four of our quality criteria demonstrated an elevated risk of 1.75 in women [19]. All the studies were based on general population samples and were of reasonable quality. 


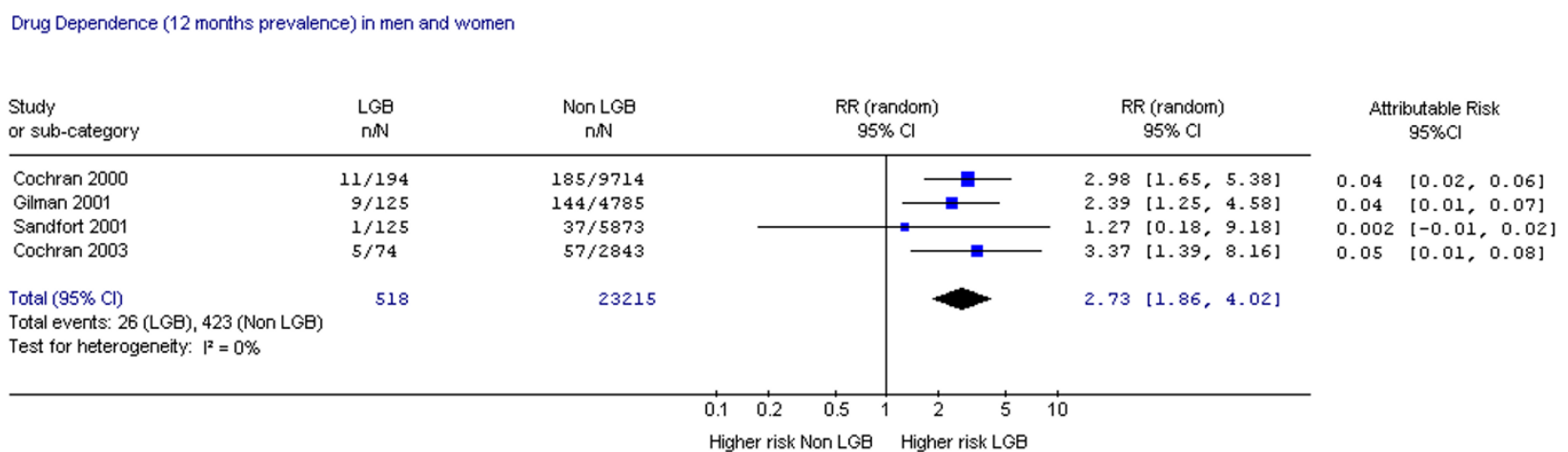

Drug Dependence (12 months prevalence) in men only

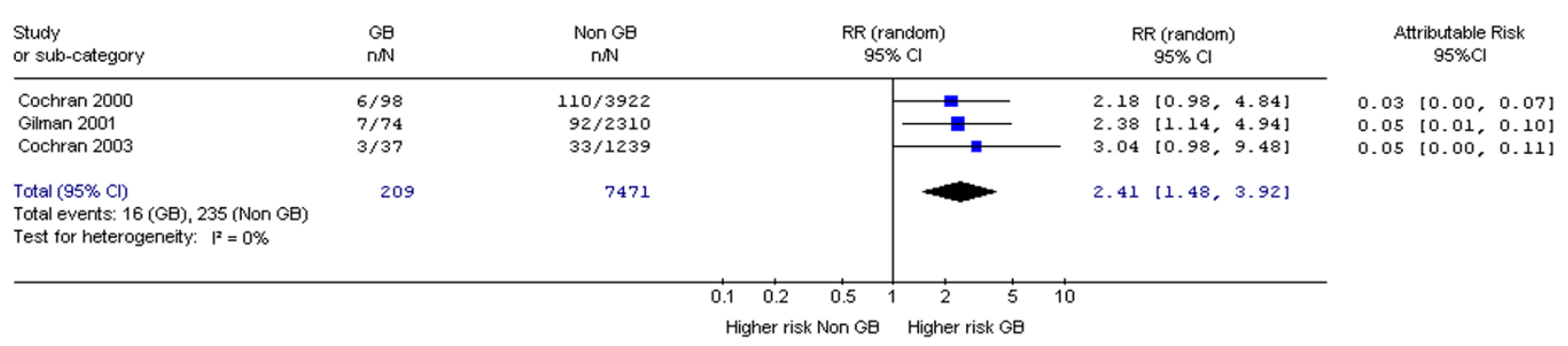

Drug Dependence ( 12 months prevalence) in women only

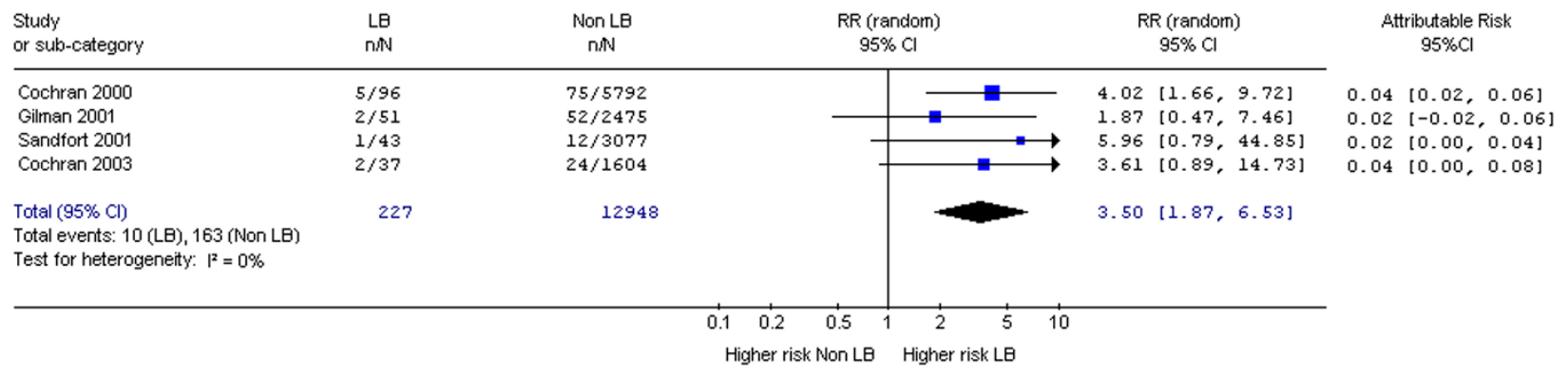

\section{Figure 8}

Forest plots for 12 month prevalence of drug dependence.

In summary, on the basis of studies of relatively good quality, there was an elevated risk of lifetime and 12 month prevalence of depression and anxiety disorders in all LGB groups compared to heterosexual controls.

\section{Alcohol misuse}

Data from a single study that met all but one of our highest quality criteria showed increased risk of lifetime prevalence of alcohol dependence in both sexes (RR $2.59 \mathrm{CI}$ $1.62,4.15$ ) and women (RR 6.51, CI 2.74, 15.44) but not in men (RR 1.60, CI 0.91, 2.80) [31]. All the studies in this analysis met at least three of our four quality criteria. Risk ratios for alcohol dependence in the previous 12 months in both sexes ranged from 1.76 to 3.05 and were higher in women (Figure 8). Attributable risk for alcohol dependence over 12 months was higher in women (Figure 8). Two studies presented data in accordance with our definition of alcohol misuse within the previous 12 months. McCabe et al (2003) [25] reported little difference between LGB people and controls, but Gruskin et al (2001) [20] reported higher risk of alcohol misuse (RR 3.52 , CI 1.97, 6.26) in LB than heterosexual women, with an attributable risk of $7 \%$.

\section{Drug misuse or any substance misuse disorder}

One study reported higher risks of lifetime prevalence of drug dependence in both sexes (RR 4.32, CI 2.14, 8.72), men (RR 2.71, CI 1.01, 7.37) and in women (RR 7.74, CI 


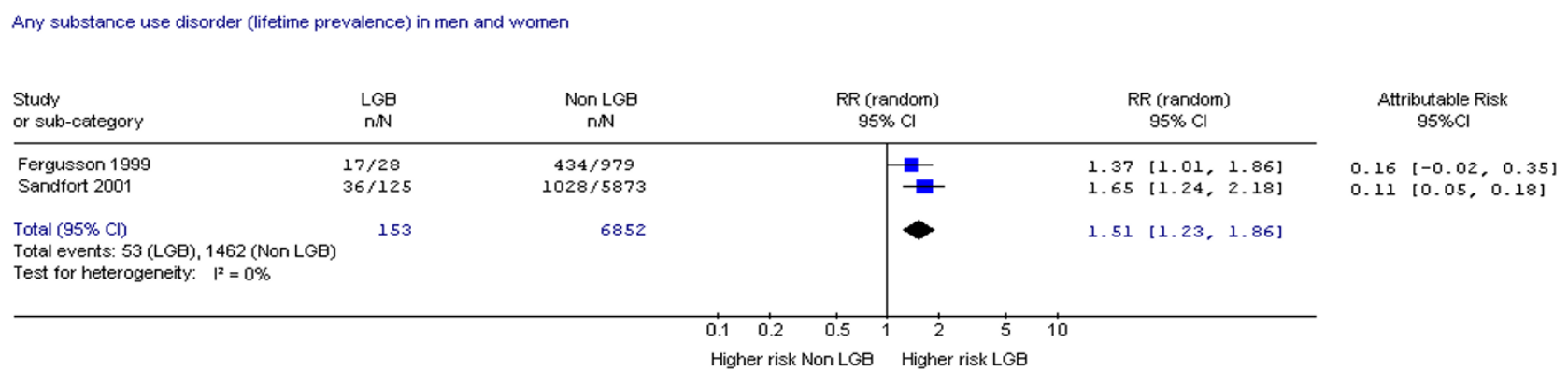

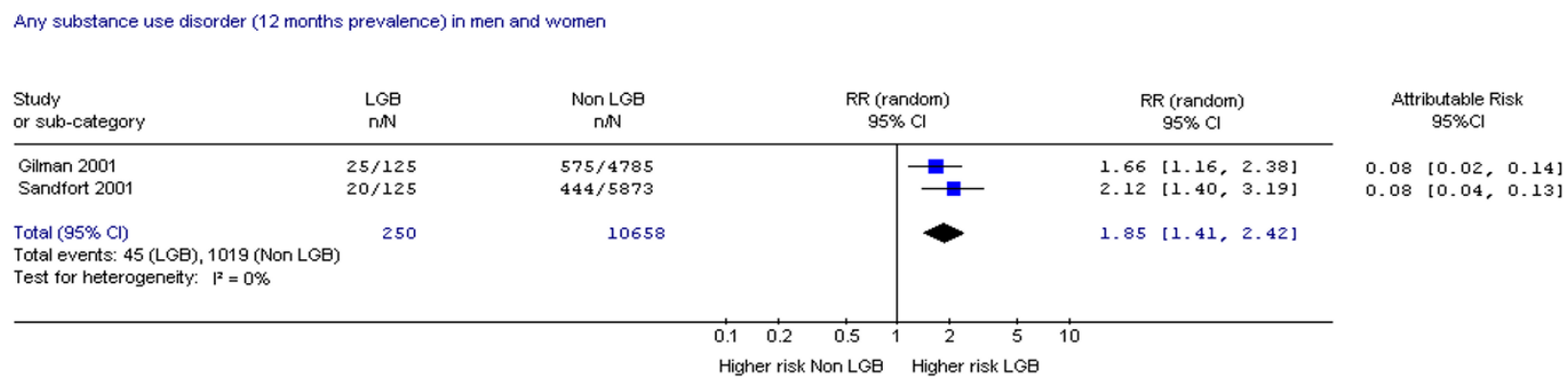

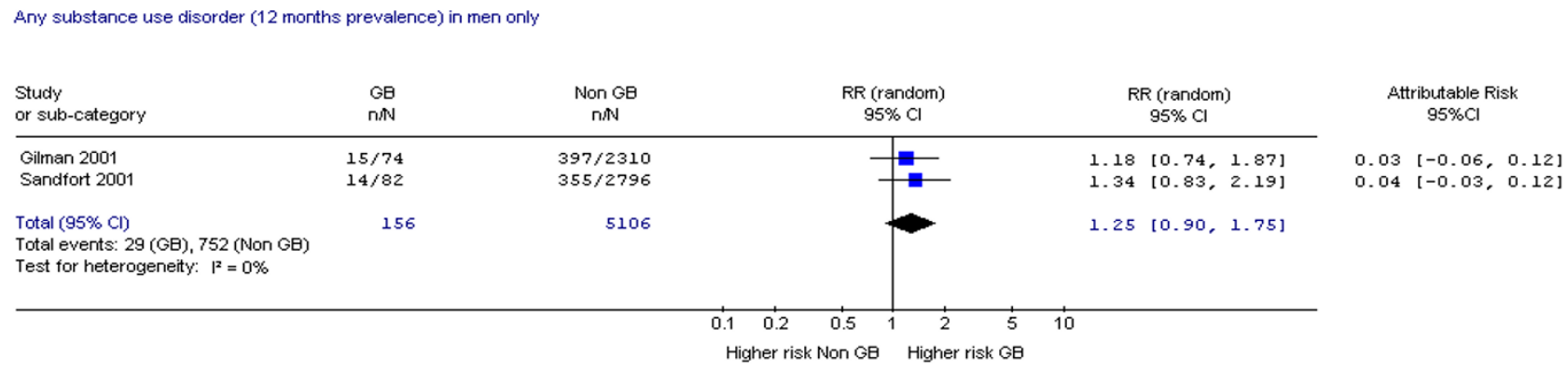

Any substance use disorder (12 months prevalence) in women only

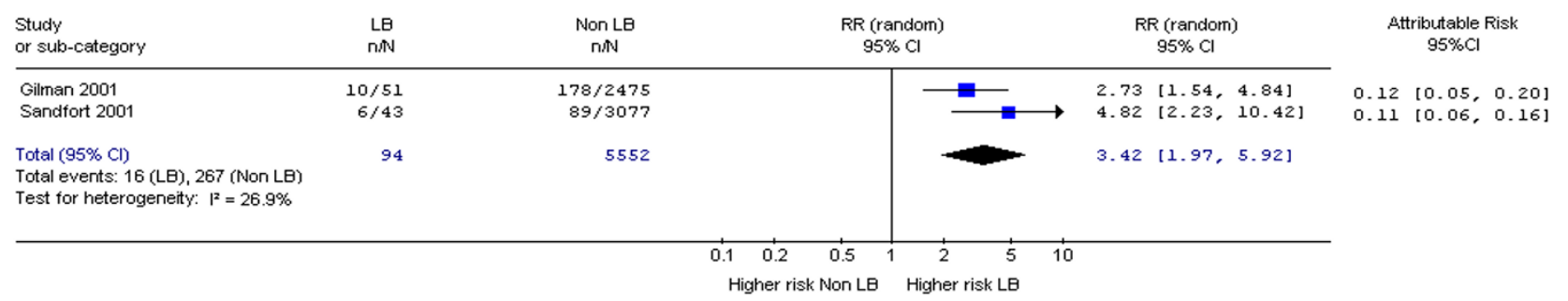

\section{Figure 9}

Forest plots for lifetime and 12 month prevalence of any substance use disorder.

$2.88,20.75)[31]$. Meta-analyses of data on drug dependence over the previous 12 months showed 2.73 times greater risk in both sexes, 3.5 times greater in women and 2.41 times greater in men than controls (Figure 9). Attributable risk for drug dependence in the previous 12 months ranged from 0.002 to 0.05 in both sexes, in men 0.03 to 0.05 and women 0.02 to 0.04 (Figure 9).
One good quality study [31] of lifetime prevalence of any substance use disorder showed elevated risk in women (RR 3.61 CI 2.13, 6.11, attributable risk 0.11 to 0.26 ) but not men (RR 1.05, CI 0.76, 1.47; attributable risk -0.08 to $0.11)$. Similar findings arose in the meta-analyses of data from two good quality studies on 12 months prevalence of any substance use disorder (figure 9). 
Table I: Classification of quality indicators of studies included in the review

\begin{tabular}{|c|c|c|c|c|}
\hline & $\begin{array}{l}\text { Sampling } \\
1=\text { Non-random } \\
2 \text { = Random }\end{array}$ & $\begin{array}{l}\text { Participation rate } \\
1<60 \% \\
2 \geq 60 \%\end{array}$ & $\begin{array}{l}\text { Population } \\
1=\text { Selected } \\
2=\text { General }\end{array}$ & $\begin{array}{l}\text { Sample size } \\
1<100 \\
2 \geq 100\end{array}$ \\
\hline Bagley $1997[9]$ & 2 & 2 & 2 & I \\
\hline Bontempo \& D'Augelli 2002 [10] & Not known & 2 & 1 & 2 \\
\hline Case et al. $2004[\mathrm{II}]^{*}$ & I & 2 & I & 2 \\
\hline Cochran \& Mays (2000a) \& Mays, Ross $(2004)[12,13]$ & I & 2 & 2 & 1 \\
\hline Cochran \& Mays (2000b) [14] & I & 2 & 2 & 1 \\
\hline Cochran et al. 2003 \& Mays \& Cochran $(2001)[15,16]$ & 2 & 2 & 2 & I \\
\hline Faulkner et al. (1998) [17] & Not known & 1 & I & 2 \\
\hline Fergusson et al $1999[18]^{*}$ & 1 & 2 & I & 1 \\
\hline Gilman et al. 200I [19] & 2 & 2 & 2 & 2 \\
\hline Gruskin et al. 200I [20] & 2 & 1 & 2 & 2 \\
\hline Herrell et al. $1999[21]$ & Not known & 2 & 1 & 2 \\
\hline Jorm et al. 2002 [22] & 2 & I & 2 & 2 \\
\hline King et al. $2003[\mathrm{I}]$ & I & NA & I & 2 \\
\hline Mathy 2002 [23] & I & 1 & 1 & 2 \\
\hline Mathews et al. 2002 [24] & I & I & I & 2 \\
\hline McCabe et al. 2003 [25] & 2 & I & I & 2 \\
\hline Mc Cabe et al. 2004 [26] & 2 & 1 & I & 1 \\
\hline Nawyn et al. 2000 [27] & Not known & i & I & I \\
\hline Remafedi et al. 1998 [28] & Not known & 2 & I & 2 \\
\hline Robin et al. 2002 [29] & Not known & 2 & I & 2 \\
\hline Russell \& Joyner 200I [30] & Not known & Not known & I & 2 \\
\hline Sandfort et al. 200I \& Sandfort, de Graf, Bijl (2003) [31,32] & 2 & 2 & 2 & I \\
\hline Skegg et al. 2003 [33]* & 1 & 2 & I & I \\
\hline Wichstrom \& Hegna 2003 [34]* & i & 2 & i & 2 \\
\hline Drabble et al. 2005 [35] & 2 & Not known & 2 & 2 \\
\hline
\end{tabular}

Key: * Longitudinal studies; 2 suggests higher quality and than I

In summary, there was an increased lifetime and 12 month risk of alcohol and drug dependency in all groups compared with heterosexuals with markedly higher risk in lesbian and bisexual women.

\section{Discussion}

LGB people are at higher risk of suicidal behaviour, mental disorder and substance misuse and dependence than heterosexual people. The results of the meta-analyses demonstrate a two fold excess in risk of suicide attempts in the preceding year in men and women, and a four fold excess in risk in gay and bisexual men over a lifetime. Similarly, depression, anxiety, alcohol and substance misuse were at least 1.5 times more common in LGB people. Findings were similar in men and women but LB women were at particular risk of substance dependence, while lifetime risk of suicide attempts was especially high in GB men.

\section{Strengths and limitations of the review}

We found 25 studies that met our inclusion criteria for epidemiological rather than clinical studies. Our search terms included all possible subcategories of mental disorder and substance dependence. We identified a wide range of study methods but excluded designs that provided biased or erroneous estimates. We included studies with consistent definitions of sexual orientation and with contemporaneous comparison groups. However, the lower than expected prevalence of LGB people in several of the population surveys $[27,31,32]$ indicates that many studies were unable to recruit a representative sample. Thus, it is likely that a proportion of LGB people are reluctant to participate in research for all sorts of reasons, but most likely for fear of disclosure. Until it becomes less risky to identify oneself as LGB for the purposes of research we shall know little about this hidden population or how it influences the conclusions we can make here. All studies used welldescribed and potentially replicable mental health outcomes. However, only one study met all four of our quality criteria, while seven met all but one of our quality markers. The number of studies in each meta-analysis was relatively small and thus we were unable to interpret funnel plots to investigate sources of bias or run a metaregression analysis to account for the variable quality of the studies identified in this review.

Given the range of study design and definitions of exposure and outcome, we encountered significant heterogeneity in our meta-analyses. However, these estimates did not deviate markedly from data reported in the better 
quality studies. Although, in some studies reported data were weighted or shown as percentages, our calculated risk ratios were similar to unadjusted ratios reported in these papers making it unlikely that we have extrapolated beyond the studies' findings. The distinction between suicide attempt and DSH was often unclear. We followed authors' definitions of the acts and did not judge the life threatening nature of the behaviour. Finally, uncertainties inherent in defining and recruiting a representative sample of LGB people cannot be overcome in a systematic review. For example, participants may be asked about their sexuality in ways that are unfamiliar to them or it may be assumed that sexual orientation is a fixed life-time characteristic. Despite these reservations about our review, the consistent direction of our findings suggests that mental health is poorer in LGB people.

\section{Selection of studies}

We had to exclude otherwise well conducted research that was based in specialised populations or in health services or that selected LGB people in a particular way. We wish to highlight three studies that we eventually excluded on grounds of selection of the LGB population [36-38]; but whose results were broadly in the direction of our findings. Russell \& Keel (2002) [36] reported data on depression using the Beck Depression Inventory; van Heeringen \& Vincke (2000) [38] reported data on suicide attempts and ideation and Savin-Williams (2001) [37] reported data on suicide attempts.

\section{Explanations for our findings}

Our study aimed to determine whether there was unequivocal evidence for a preponderance of mental health problems in LGB people relative to heterosexuals. Thus, circumspection is required when discussing possible mechanisms which generate them [120]. Although our evidence does not specify the nature of such mechanisms, there is no evidence to suggest that homosexuality is itself a disorder that is thereby subject to a higher co-morbidity than is found in heterosexuals [120]. This review was strictly limited to documenting whether or not there was an excess of mental health problems in LGB people. It will take other, prospective research to investigate the components of this vulnerability. Unfortunately prospective studies were unusual among the 25 reviewed here and thus we cannot say much with certainty about the risk factors for mental disorder in LGB people. Nevertheless, it is likely that the social hostility, stigma and discrimination that most LGB people experience is at least part of the reason for the higher rates of psychological morbidity observed. This may be aggravated by easy access to alcohol and drugs in gay venues that LGB people frequent both to find the company of others who will accept them less critically and to meet potential partners. However, why LB women are at greater risk of substance misuse than GB men is not clear as most LGB commercial venues provide alcohol.

\section{Implications of our findings}

It is of considerable concern that sexual minorities such as LGB people suffer so many disadvantages in terms of mental health. Our findings need consideration in planning public health and clinical services, as well as in terms of international human rights. Although we cannot report on whether or not LGB people are at greater risk than heterosexuals for completed suicide, the elevated risks for all forms of mental disorder, DSH and substance misuse would suggest very strongly that this is the case. Thus, national suicide strategies need to include LGB people as a high risk group now rather than await more evidence on suicide. The hidden nature of sexual orientation makes it very unlikely that we shall be able to show definitely in post-mortem psychological studies that LGB are over-represented among suicide victims.

\section{Conclusion and further research}

Besides more qualitative and case-control research, we need prospective studies as these are most likely to reveal the mechanisms involved. Although, in this review we identified four cohorts $[15,18,33,34]$ only one collected prospective data on suicidal risk in lesbian, gay and bisexual people [34]. Prospective studies, however, are difficult to undertake as many people cannot or will not identify themselves as LGB until late adolescence or even young adulthood when the emotional damage may already have occurred. Nevertheless, a cohort of young LGB people who are followed through as they complete education and career training and start relationships and families, would begin to address this difficult issue. We also need to address the complexities of defining sexual orientation. Most modern conceptions of sexual orientation consider personal identification, sexual behaviour and sexual fantasy [121]. Thus, we chose these parameters as the most pragmatic and commonly used definitions for this review. However, we need more detailed study of the development of sexuality across the spectrum of partner preference, its stability over time and its relationship to other preferences and behaviour.

\section{Competing interests}

The authors declare that they have no competing interests

\section{Authors' contributions}

MK, HK, DO, IN and SST obtained funding for the study. JS and DP conducted the literature search, obtained papers and extracted data. JS, MK, HK, DO, IN and DP scanned abstracts and read papers. SST conducted the meta-analysis with input from IN and MK. MK drafted the 
paper and all authors contributed to the final version. All authors read and approved the final version.

\section{Additional material}

\section{Additional File 1}

Table 1: review studies.

Click here for file

[http://www.biomedcentral.com/content/supplementary/1471244X-8-70-S1.doc]

\section{Acknowledgements}

The study was funded by a grant from the National Institute for Mental Health England. The funder had no involvement in the conduct of the research. We thank Rosalind Lai M Lib, Medical Librarian, for constructing the search strategy.

\section{References}

I. King M, McKeown E, Warner J, Ramsay A, Johnson K, Cort C, Wright L, Blizard R, Davidson O: Mental health and quality of life of gay men and lesbians in England and Wales: a controlled, crosssectional study. British Journal of Psychiatry 2003, 183:552-558.

2. Meyer IH: Prejudice, social stress and mental health in lesbian, gay and bisexual populations: conceptual issues and research evidence. Psychological Bulletin 2003, I 29:674-697.

3. Gibson P: Gay male and lesbian youth suicide. US Department of Health and Human Services: Report of the Secretary's Task Force on Youth Suicide. Volume 3. Washington DC, Government Printing Office; 1989: I 15-|42.

4. NHS Centre for Reviews and Dissemination Deliberate Self Harm. 1989, 4(6):

5. National Institute for Mental Health in England: National Suicide Prevention Strategy for England. Annual Report on Progress 2006.

6. Kinsey AC, Pomeroy WB, Martin CE: Sexual behaviour in the Human Male. Saunders, Philadelphia; 1948

7. Egger M, Schneider M, Davey-Smith G: Spurious precision? Metaanalysis of observational studies. British Medical Journal 1998, 316:140-144.

8. Higgins JPT, Thompson SG, Deeks JJ, Altman DG: Measuring inconsistency in meta-analyses. British Medical Journal 2003, 327:557-560.

9. Bagley C, Tremblay P: Suicidal behaviors in homosexual and bisexual males. Crisis 1997, 18(1):24-34.

10. Bontempo DE, D'Augelli AR: Effects of at-school victimization and sexual orientation on lesbian, gay, or bisexual youths' health risk behavior. Journal of Adolescent Health 2002, 30(5):364-374.

II. Case P, Bryn Austin S, Hunter DJ, Manson JE, Malspeis S, Willett W, Speigelman D: Sexual Orientation, Health Risk Factors, and Physical Functioning in the Nurses' Health Study II. Journal of Women's Health 2004, 13:1033-1047.

12. Cochran SD, Mays VM: Relation between psychiatric syndromes and behaviorally defined sexual orientation in a sample of the US population. American Journal of Epidemiology 2000, I5 I(5):516-523.

13. Cochran SD, Ackerman D, Mays VM, Ross MW: Prevalence of non-medical drug use and dependence among homosexually active men and women in the US population. Addiction 2004, 99(8):989-998.

14. Cochran SD, Mays VM: Lifetime prevalence of suicide symptoms and affective disorders among men reporting same-sex sexual partners: Results from NHANES III. American Journal of Public Health 2000, 90(4):573-578.

15. Cochran SD, Sullivan JG, Mays VM: Prevalence of mental disorders, psychological distress, and mental services use among lesbian, gay, and bisexual adults in the United States. Journal of Consulting and Clinical Psychology 2003, 7 I(I):53-6I.
16. Mays VM, Cochran SD: Mental health correlates of perceived discrimination among lesbian, gay, and bisexual adults in the United States. American Journal of Public Health 200I, 9I(I I): 1869-1876.

17. Faulkner $\mathrm{AH}, \mathrm{Cranston} \mathrm{K}$ : Correlates of same-sex sexual behavior in a random sample of Massachusetts high school students. American Journal of Public Health 1998, 88(2):262-266.

18. Fergusson DM, Horwood LJ, Beautrais AL: Is sexual orientation related to mental health problems and suicidality in young people? Archives of General Psychiatry 1999, 56(10):876-880.

19. Gilman SE, Cochran SD, Mays VM, Hughes M, Ostrow D, Kessler RC: Risk of psychiatric disorders among individuals reporting same-sex sexual partners in the National Comorbidity Survey. American Journal of Public Health 200I, 9 I (6):933-939.

20. Gruskin EP, Hart S, Gordon N, Ackerson L: Patterns of cigarette smoking and alcohol use among lesbians and bisexual women enrolled in a large health maintenance organization. American Journal of Public Health 200I, 9 I (6):976.

21. Herrell R, Goldberg J, True WR, Ramakrishnan V, Lyons M, Eisen S, Tsuang MT: Sexual orientation and suicidality: a co-twin control study in adult men. Archives of General Psychiatry 1999, 56(10):867-874.

22. Jorm AF, Korten AE, Rodgers B, Jacomb PA, Christensen H: Sexual orientation and mental health: results from a community survey of young and middle-aged adults. British Journal of Psychiatry 2002, 1 80(5):423-427.

23. Mathy RM: Suicidality and sexual orientation in five continents: Asia, Australia, Europe, North America, and South America. International Journal of Sexuality and Gender Studies 2002, 7(2-3):215-225.

24. Matthews AK, Hughes TL, Johnson T, Razzano LA, Cassidy R: Prediction of depressive distress in a community sample of women: The role of sexual orientation. American Journal of Public Health 2002, 92(7): I I3I-I I39.

25. McCabe SE, Boyd C, Hughes TL, D'Arcy H: Sexual identity and substance use among undergraduate students. Substance Abuse 2003, 24(2):77-9I.

26. McCabe SE, Hughes TL, Boyd CJ: Substance use and misuse: are bisexual women at greater risk? Journal of Psychoactive Drugs 2004, 36(2):217-225.

27. Nawyn SJ, Richman JA, Rospenda KM, Hughes TL: Sexual identity and alcohol-related outcomes: contributions of workplace harassment. Journal of Substance Abuse 2000, I I (3):289-304.

28. Remafedi G, French S, Story M, Resnick MD, Blum R: The relationship between suicide risk and sexual orientation: results of a population-based study. American Journal of Public Health 1998, 88(I):57-60.

29. Robin L, Brener ND, Donahue SF, Hack T, Hale K, Goodenow C: Associations between health risk behaviors and opposite-, same-, and both-sex sexual partners in representative samples of Vermont and Massachusetts high school students. Archives of Pediatrics \& Adolescent Medicine 2002, I 56(4):349-355.

30. Russell ST, Joyner K: Adolescent sexual orientation and suicide risk: evidence from a national study. American Journal of Public Health 200I, 9 I(8): I276-I28I.

3I. Sandfort TG, de Graaf R, Bijl RV, Schnabel P: Same-sex sexual behavior and psychiatric disorders: Findings from the Netherlands mental health survey and incidence study (NEMESIS). Archives of General Psychiatry 200I, 58(I):85-9I.

32. Sandfort TG, De Graaf R, Bijl RV: Same-sex sexuality and quality of life: findings from the Netherlands Mental Health Survey and Incidence Study. Archives of Sexual Behaviour 2003, 32(I): $15-22$.

33. Skegg K, Nada-Raja S, Dickson N, Paul C, Williams S: Sexual orientation and self-harm in men and women. American Journal of Psychiatry 2003, 160(3):54I-546

34. Wichstrom L, Hegna K: Sexual orientation and suicide attempt: A longitudinal study of the general Norwegian adolescent population. Journal of Abnormal Psychology 2003, II 2(I): | 144-I5I.

35. Drabble L, Midanik LT, Trocki K: reports of alcohol consumption and alcohol-related problems among homosexual, bisexual and heterosexual respondents: results from the $\mathbf{2 0 0 0}$ national alcohol survey. I Stud Alcohol 2005, 66(I): I I I- I 20.

36. Russell CJ, Keel PK: Homosexuality as a specific risk factor for eating disorders in men. International Journal of Eating Disorders 2002, 3 I (3):300-306 
37. Savin-Williams RC: Suicide attempts among sexual-minority youths: Population and measurement issues. Journal of Consulting and Clinical Psychology 2001, 69(6):983-991.

38. van Heeringen $C$, Vincke J: Suicidal acts and ideation in homosexual and bisexual young people: A study of prevalence and risk factors. Social Psychiatry and Psychiatric Epidemiology 2000, 35( I I ):494-499.

39. Garofalo R, Wolf RC, Kessel S, Palfrey SJ, DuRant RH: The association between health risk behaviors and sexual orientation among a school-based sample of adolescents. Pediatrics 1998, I 0 I(5):895-902.

40. Garofalo R, Wolf RC, Wissow LS, Woods ER, Goodman E: Sexual orientation and risk of suicide attempts among a representative sample of youth. Archives of Pediatrics and Adolescent Medicine I999, I 53(5):487-493.

4I. Austin SB, Ziyadeh N, Kahn JA, Camargo CAJ, Colditz GA, Field A: Sexual orientation, weight concerns, and eating-disordered behaviors in adolescent girls and boys. Journal of the American Academy of Child \& Adolescent Psychiatry 2004, 43(9): I I I 5- I I 23.

42. Bernhard LA, Applegate JM: Comparison of stress and stress management strategies between lesbian and heterosexual women. Health Care for Women International 1999, 20(4):335-347.

43. Bloomfield K: A comparison of alcohol consumption between lesbians and heterosexual women in an urban population. Drug and Alcohol Dependence 1993, 33(3):257-269.

44. Boyd C], McCabe SE, D'Arcy H: Ecstasy use among college undergraduates: Gender, race and sexual identity. Journal of Substance Abuse Treatment 2003, 24(3):209-215.

45. Burgard SA, Cochran SD, Mays VM: Alcohol and tobacco use patterns among heterosexually and homosexually experienced California women. Drug and Alcohol Dependence 2005, 77(I):6I-70.

46. Conner M, Johnson C, Grogan S: Gender, sexuality, body image and eating behaviours. Journal of Health Psychology 2004, 9(4):505-5 I5

47. Diamant AL, Wold C: Sexual orientation and variation in physical and mental health status among women. Journal of Women's Health 2003, I 2(I):4 I-49.

48. Duggan SJ, McCreary DR: Body image, eating disorders, and the drive for muscularity in gay and heterosexual men: the influence of media images. Journal of Homosexuality 2004, 47(34):45-58.

49. Eisenberg $M$, Wechsler $H$ : Substance use behaviors among college students with same-sex and opposite -sex experience: results from a national study. Addictive Behavior 2003, 28(5):899-9|3.

50. Eisenberg ME, Wechsler $\mathrm{H}$ : Social influences on substance-use behaviors of gay, lesbian, and bisexual college students: findings from a national study. Social Science and Medicine 2003, 57(10): 1913-1923.

5I. Fendrich M, Wislar JS, Johnson TP, Hubbell A: A contextual profile of club drug use among adults in Chicago. Addiction 2003, 98(I 2): I 693-I703.

52. French SA, Story M, Remafedi G, Resnick MD, Blum RW: Sexual orientation and prevalence of body dissatisfaction and eating disordered behaviors: a population-based study of adolescents. International Journal of Eating Disorders 1996, I 9(2): I I9-I 26.

53. Herzog DB, Newman KL, Warshaw M: Body image dissatisfaction in homosexual and heterosexual males. J Nerv Ment Dis I99I, I 79(6):356-359.

54. Herzog DB, Newman KL, Yeh CJ, Warshaw M: Body image satisfaction in homosexual and heterosexual women. International Journal of Eating Disorders 1992, I I(4):391-396.

55. Hillier L, De Visser R, Kavanagh AM, McNair RP: The association between licit and illicit drug use and sexuality in young Australian women. Medical Journal of Australia 2003, I 79(6):326-327.

56. Lakkis J, Ricciardelli LA, Williams RJ: Role of sexual orientation and gender-related traits in disordered eating. Sex Roles 1999, 4 I (I-2): I- I6.

57. Lock J, Steiner H: Gay, lesbian, and bisexual youth risks for emotional, physical, and social problems: Results from a community-based survey. Journal of the American Academy of Child and Adolescent Psychiatry 1999, 38(3):297-304.

58. Matthews AK, Hughes TL: Mental health service use by African American women: exploration of subpopulation differences. Cultural Diversity and Ethnic Minority Psychology 200I, 7( I):75-87.
59. Meyer C, Blissett J, Oldfield C: Sexual orientation and eating psychopathology: the role of masculinity and femininity. International Journal of Eating Disorders 200I, 29(3):3।4-3 I8.

60. Moore F, Keel PK: Influence of sexual orientation and age on disordered eating attitudes and behaviors in women. International Journal of Eating Disorders 2003, 34(3):370-374.

6I. Neumark-Sztainer D, Story M, Toporoff E, Cassuto N, Resnick MD, Blum RW: Psychosocial predictors of binge eating and purging behaviors among adolescents with and without Diabetes Mellitus. Journal of Adolescent Health 1996, I 9(4):289-296.

62. Neumark Sztainer D, Story M, Resnick MD, Blum RW: Lessons learned about adolescent nutrition from the Minnesota Adolescent Health Survey. Journal of the American Dietetic Association 1998, 98( I 2): |449-|456.

63. Oberstone AK, Sukoneck $\mathrm{H}$ : Psychological adjustment and life style of single lesbians and single heterosexual women. Psychology of Women Quarterly 1976, I(2): |72-I88.

64. Russell ST, Driscoll AK, Truong N: Adolescent same-sex romantic attractions and relationships: implications for substance use and abuse. American Journal of Public Health 2002 , 92(2): 198-202.

65. Scheer S, Peterson I, Page SK, Delgado V, Gleghorn A, Ruiz J, Molitor F, McFarland W, Klausner J, the Young Women's Survey Team: Sexual and drug use behavior among women who have sex with both women and men: results of a population-based survey. American Journal of Public Health 2002, 92(7): I I I 0- I I I 2.

66. Schneider JA, O'Leary A, Jenkins SR: Gender, sexual orientation, and disordered eating. Psychology and Health 1995, I0(2): I I3-128

67. Share TL, Mintz LB: Differences between lesbians and heterosexual women in disordered eating and related attitudes. Journal of Homosexuality 2002, 42(4):89-106.

68. Siever MD: Sexual orientation and gender as factors in socioculturally acquired vulnerability to body dissatisfaction and eating disorders. Journal of Consulting and Clinical Psychology 1994, 62(2):252-260

69. Silberstein LR, Mishkind ME, Striegel-Moore RH, Timko C: Men and their bodies: A comparison of homosexual and heterosexual men. Psychosomatic Medicine 1989, 5 I(3):337-346.

70. Smith AM, Lindsay J, Rosenthal DA: Same-sex attraction, drug injection and binge drinking among Australian adolescents. Australian and New Zealand Journal of Public Health 1999, 23(6):643-646

7I. Stall R, Wiley J: A comparison of alcohol and drug use patterns of homosexual and heterosexual men: the San Francisco Men's Health Study. Drug and Alcohol Dependence 1988, 22(I2):63-73.

72. Williamson I, Hartley P: British research into the increased vulnerability of young gay men to eating disturbance and body dissatisfaction. European Eating Disorders Review 1998, 6(3): $160-170$

73. Woody GE, VanEtten Lee ML, McKirnan D, Donnell D, Metzger D, Seage G 3rd, Gross M, HIVNET VPS 00I Protocol Team: Substance use among men who have sex with men: comparison with a national household survey. J Acquir Immune Defic Syndr 200I, 27(1):86-90.

74. Yelland C, Tiggemann M: Muscularity and the gay ideal: Body dissatisfaction and disordered eating in homosexual men. Eating Behaviors 2003, 4(2): I07-I I6.

75. Avery AM, Hellman RE, Sudderth LK: Satisfaction with mental health services among sexual minorities with major mental illness. American Journal of Public Health 200 I, 9 I (6):990-99I.

76. Kuang MF, Mathy RM, Carol HM, Nojima K: The Effects of Sexual Orientation, Gender Identity, and Gender Role on the Mental Health of Women in Taiwan's T-Po Lesbian Community. Journal of Psychology and Human Sexuality 2003, I 5(4): I 63-I84.

77. Barney DD: Health risk-factors for gay American Indian and Alaska Native adolescent males. Journal of Homosexuality 2003, 46(I-2): I37-I57.

78. Biernbaum MA, Ruscio M: Differences between matched heterosexual and non-heterosexual college students on defense mechanisms and psychopathological symptoms. Journal of Homosexuality 2004, 48(I): | 25-|4|.

79. Carlat DJ, Camargo CAJ, Herzog DB: Eating disorders in males: a report on 135 patients. American Journal of Psychiatry 1997 , | 54(8): | | $27-$ | | 32 
80. Clark TR: Homosexuality and psychopathology in nonpatient males. American Journal of Psychoanalysis 1975, 35(2): I63-I68.

81. Copeland J, Hall W, Didcott P, Biggs V: A comparison of a specialist women's alcohol and other drug treatment service with two traditional mixed-sex services: client characteristics and treatment outcome. Drug and Alcohol Dependence 1993, 32(I):8I-92.

82. Garcia J, Adams J, Friedman L, East P: Links between past abuse, suicide ideation, and sexual orientation among San Diego college students. Journal of American College Health 2002, 5 I (I):9-14.

83. Hellman RE, Sudderth L, Avery AM: Major Mental Illness in a Sexual Minority Psychiatric Sample. Journal of the Gay and Lesbian Medical Association 2002, 6(3-4):97-106.

84. Hirsch JK, Ellis JB: Reasons for living in homosexual and heterosexual young adults. Archives of Suicide Research 1998, 4(3):243-248.

85. Holleran PR, Novak AH: Support choices and abstinence in gayl lesbian and heterosexual alcoholics. Alcoholism Treatment Quarterly 1989, 6(2):7I-83.

86. Hopkins $\mathrm{JH}$ : The lesbian personality. British Journal of Psychiatry | 969, I I 5(529): | 433-|436.

87. Hughes TL: Lesbians' Drinking Patterns: Beyond the Data. Substance Use and Misuse 2003, 38( I I-13):1739-1758.

88. Kruks G: Gay and lesbian homeless/street youth: Special issues and concerns. Journal of Adolescent Health 1991, I 2(7):515-518.

89. Leslie MB, Stein JA, Rotheram-Borus MJ: Sex-specific predictors of suicidality among runaway youth. I Clin Child Adolesc Psychol 2002, 3 I (I):27-40.

90. Lewis CE, Saghir MT, Robins E: Drinking patterns in homosexual and heterosexual women. Journal of Clinical Psychiatry 1982, 43(7):277-279.

91. Mangweth B, Pope HG], Hudson Jl, Olivardia R, Kinzl J, Biebl W: Eating disorders in Austrian men: An intracultural and crosscultural comparison study. Psychother Psychosom 1997, 66(4):2|4-22|.

92. Martin RL, Cloninger CR, Guze SB, Clayton PJ: Mortality in a follow-up of 500 psychiatric outpatients. I. Total mortality. Archives of General Psychiatry 1985, 42(I):47-54.

93. Mathy RM, Lehmann BA: Public health consequences of the defense of marriage act for lesbian and bisexual women: Suicidality, behavioral difficulties, and psychiatric treatment. Feminism and Psychology 2004, I 4(I): I87-194.

94. Noell JW, Ochs LM: Relationship of sexual orientation to substance use, suicidal ideation, suicide attempts, and other factors in a population of homeless adolescents. Journal of Adolescent Health 200I, 29(I):31-36.

95. Nurius PS: Mental health implications of sexual orientation. Journal of Sex Research 1983, I9(2): I19-136.

96. Paris J, Zweig FH, Guzder J: Psychological factors associated with homosexuality in males with borderline personality disorder. Journal of Personality Disorders 1995, 9(I):56-6I.

97. Pillard RC: Sexual orientation and mental disorder. Psychiatric Annals 1988, I 8(I):52-56.

98. Rutter PA, Soucar E: Youth suicide risk and sexual orientation. Adolescence 2002, 37( I 46):289-299.

99. Safren SA, Heimberg RG: Depression, hopelessness, suicidality, and related factors in sexual minority and heterosexual adolescents. Journal of Consulting and Clinical Psychology 1999, 67(6):859-866.

100. Saghir MT, Robins E, Walbran B, Gentry KA: Homosexuality. III. Psychiatric disorders and disability in the male homosexual. American Journal of Psychiatry 1970, I 26(8): I079-1086.

I0I. Saghir MT, Robins E, Walbran B, Gentry KA: Homosexuality. IV. Psychiatric disorders and disability in the female homosexual. American Journal of Psychiatry 1970, I27(2): |47-I54.

102. Saulnier CF, Miller BA: Drug and alcohol problems: heterosexual compared to lesbian and bisexual women. Canadian Journal of Human Sexuality 1997, 6(3):221-23I.

103. Schmitt JP, Kurdek LA: Correlates of social anxiety in college students and homosexuals. Journal of Personality Assessment 1984, 48(4):403-409.

104. Siegelman M: Adjustment of male homosexuals and heterosexuals. Archives of Sexual Behavior 1972, 2(I):9-25.
105. Singh D, Vidaurri M, Zambarano RJ, Dabbs JMJ: Lesbian erotic role identification: Behavioral, morphological, and hormonal correlates. Journal of Personality and Social Psychology 1999, 76(6): $1035-1049$.

106. Striegel-Moore $\mathrm{RH}$, Tucker N, Hsu J: Body image dissatisfaction and disordered eating in lesbian college students. International Journal of Eating Disorders 1990, 9(5):493-500.

107. Strong SM, Williamson DA, Netemeyer RG, Geer JH: Eating disorder symptoms and concerns about body differ as a function of gender and sexual orientation. Journal of Social and Clinical Psychology 2000, I9(2):240-255.

108. Tori CD: Homosexuality and illegal residency status in relation to substance abuse and personality traits among Mexican nationals. Journal of Clinical Psychology 1989, 45(5):814-82I.

109. Tuel BD, Russell RK: Self-esteem and depression in battered women: A comparison of lesbian and heterosexual survivors. Violence Against Women 1998, 4(3):344-362.

I I0. Westefeld JS, Maples MR, Buford B, Taylor S: Gay, lesbian, and bisexual college students: The relationship between sexual orientation and depression, loneliness, and suicide. Journal of College Student Psychotherapy 200I, I 5(3):7I-82.

III. Whitbeck LB, Chen X, Hoyt DR, Tyler KA, Kurt D: Mental Disorder, Subsistence Strategies, and Victimization Among Gay, Lesbian, and Bisexual Homeless and Runaway Adolescents. Journal of Sex Research 2004, 4 I (4):329-342.

II2. Yoder KA, Hoyt DR, Whitbeck LB: Suicidal behavior among homeless and runaway adolescents. Journal of Youth and Adolescence 1998, 27(6):753-77I.

II3. Zubenko GS, George AW, Soloff PH, Schulz P: Sexual practices among patients with borderline personality disorder. American Journal of Psychiatry 1987, I 44(6):748-752.

I 14. Balsam KF, Huang B, Fieland KC, Simoni JM, Walters KL: Culture, trauma, and wellness: a comparison of heterosexual and lesbian, gay, bisexual, and two-spirit native Americans. Cultural Diversity Ethnic Minority Psychology 2004, I 0(3):287-30I.

II5. DuRant RH, Krowchuk DP, Sinal SH: Victimization, use of violence, and drug use at school among male adolescents who engage in same-sex sexual behavior. Journal of Pediatrics 1998, I33(I): I I3-I I8.

116. Mathy RM: Transgender Identity and Suicidality in a Nonclinical Sample: Sexual Orientation, Psychiatric History, and Compulsive Behaviors. Journal of Psychology and Human Sexuality 2002, I 4(4):47-65

I 17. Ndimbie OK, Perper JA, Kingsley L, Harty L, Winkelstein A: Sudden unexpected death in a male homosexual cohort. The American Journal of Forensic Medicine and Pathology I994, I 5(3):247-250.

I 18. Rich CL, Fowler RC, Young D, Blenkush M: San Diego suicide study: Comparison of gay to straight males. Suicide and Life Threatening Behavior 1986, I 6(4):448-457.

I 19. Shaffer D, Fisher P, Parides M, Gould M: Sexual orientation in adolescents who commit suicide. Suicide and Life Threatening Behavior I995, 25(Suppl):64-7I.

120. Bailey JM: Homosexuality and mental illness. Archives of General Psychiatry 1999, 56(1 0):883-884.

121. McWhirter DP, Sanders SA, Reinisch JM: Homosexuality/Heterosexuality New York: Oxford University Press; 1990.

\section{Pre-publication history}

The pre-publication history for this paper can be accessed here:

\section{http://www.biomedcentral.com/1471-244X/8/70/pre pub}

